\title{
Red Cell Distribution Width and Fall Events in Older Adults
}

\author{
Anna K. Heninger \\ A thesis \\ submitted in partial fulfillment of \\ the requirements for the degree of
}

\section{Master of Science}

\author{
University of Washington
}

2014

Committee:

Lingtak-Neander Chan

Elizabeth Kirk

Joy Plein

Program Authorized to Offer Degree:

Nutritional Sciences

School of Public Health 
(C) Copyright 2014

Anna K. Heninger 


\section{TABLE OF CONTENTS}

Page

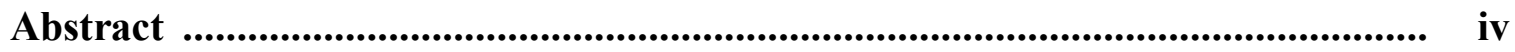

Background ….................................................................................................... 1

Red-Blood Cell Distribution Width...................................................... 1

Implications of Elevated RDW Values ............................................ 1

Proposed Mechanisms behind Elevated RDW other than Anemia ................ 4

Overview and Epidemiology of Falls in Older Adults .............................. 6

Consequences of Falls in Older Adults ............................................... 7

Assessment of Fall Risk ................................................................. 9

Deficiencies in Fall Risk Assessment Tools ............................................. 10

Factors that Increase Fall Risk ........................................................... 13

Medication Use as a Risk Factor for Fall Events ................................... 21

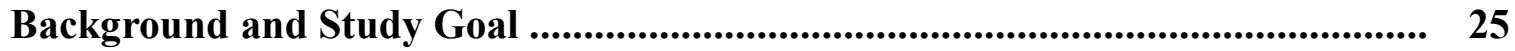

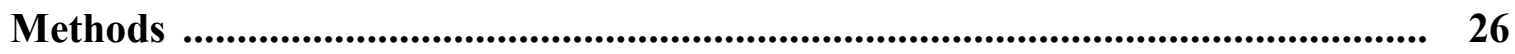

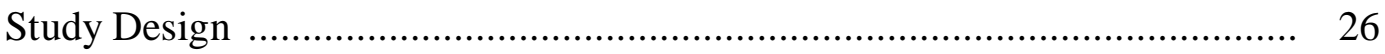

Demographic and Clinical Data Collection ............................................. 27

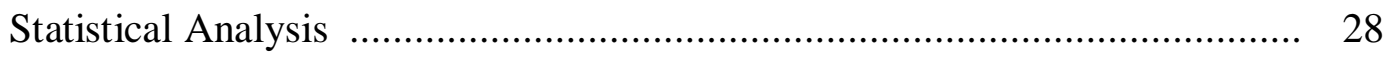

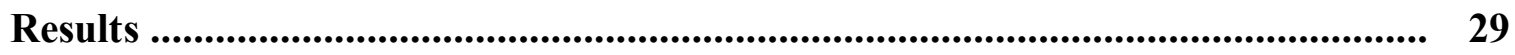

Cross-sectional Analyses .............................................................. 29

Longitudinal Analyses .............................................................. 32

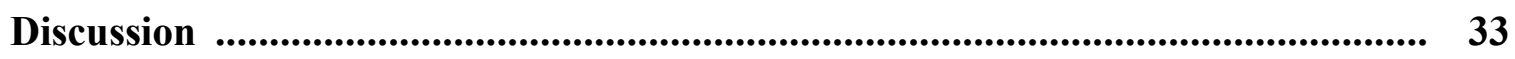

Limitations and Future Research ...................................................... 39

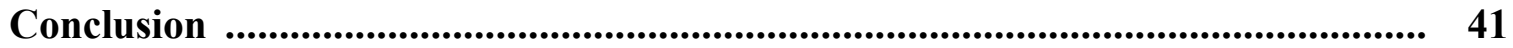

Acknowledgement and Disclosure of Conflicts of Interest .................................. 42

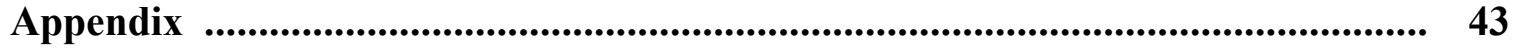

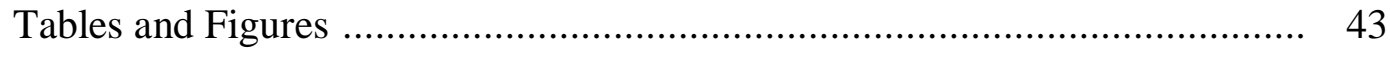

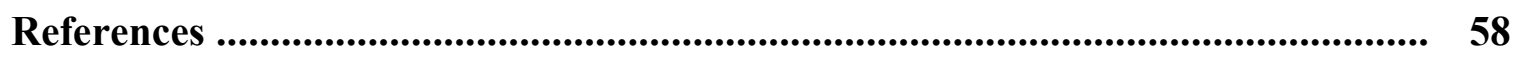




\section{Abstract}

Purpose: Red-blood cell distribution width (RDW) has been associated with negative outcomes including cardiovascular disease, diabetes, pancreatitis, liver disease, and poor pulmonary function. These diseases have also been associated with fall events in older adults. RDW is strongly associated with morbidity and mortality. This study aims to investigate the association between RDW and fall events, and the association between RDW and correlates of falls (weight, BMI, polypharmacy, vision impairment, mobility impairment, facility falls risk assessment scores) in cross-sectional and longitudinal measures in older adults.

Methods: The retrospective medical review included 92 older adults living in a nursing home for Ól year. Data was gathered from electronic and paper records on anthropometrics, functional status, fall history, diagnoses, medications, and laboratory values. Data collection points were divided into four quarterly time points for one year of data. Mono- and multivariate logistic regression were performed to assess correlates of falls.

Results: RDW ranged from 12.0 to $25.2 \%$ with an intra-subject variance of $1.01 \pm 1.49 \%$. Subjects in the highest quintile of weight had a statistically significant higher mean RDW than did those in the lower four quartiles $(P=0.02)$. The mean RDW values of subjects with a mean facility falls score of Òl 8 was significantly different from those $>18$ points $(P=0.03)$. An inverse relationship was observed between mean RDW and the total number of falls experienced by subjects. Total falls experienced by subjects during the one-year review period ranged from 0 to 13 falls with $38(41.3 \%)$ of subjects experiencing a fall during the period. None of the odds ratios for variables included in mono- or multivariate logistic regression analysis were significant according to $95 \%$ confidence intervals.

Conclusion: RDW is not associated with falls or most correlates of falls in facility-dwelling older adults. 


\section{Background}

\section{Red-Blood Cell Distribution Width}

Red-blood cell distribution width (RDW) is a quantitative assessment of the magnitude of anisocytosis of red blood cell (RBC) size. It is expressed as a coefficient of variation (CV) and plotted on a Price-Jones curve, which reflects the variability and heterogeneity of RBCs. Under normal physiology, RDW is between $11-15 \%$ in the general population. ${ }^{1}$ An increase in RDW suggests that the lack of RBC uniformity is high, with an increased proportion of RBCs that are smaller or larger than normal. RDW is part of a Complete Blood Count (CBC) laboratory panel in most institutions, and is one of the most common types of laboratory tests performed during routine check-ups. ${ }^{2,3}$ RDW is primarily used to confirm if anemia is present in conjunction with other laboratory measurements. ${ }^{1}$ Additionally, clinical data have demonstrated an association between increased RDW and pathophysiological processes in various patient populations. ${ }^{1,4}$ Higher RDW values have been associated with poor health outcomes and mortality in patients with chronic conditions, such as cardiovascular disease, diabetes, liver disease, and pancreatitis. ${ }^{5-}$ 15

\section{Implications of Elevated RDW Values}

Elevated RDW has predictive value on mortality (Hazard Ratio [HR] 1.609; 95\% Confidence Interval [CI], 1.302-1.990, $P<0.0001)$ in patients with heart failure $(n=195$, median age $=69.5$ years $)$. The strength of the association on mortality with RDW was similar to that with N-terminal brain natriuretic peptide (NT-proBNP) (HR 1.498, 95\% CI, 1.212-1.852, $P$ $=0.001)$. RDW was also associated with clinical outcomes such as re-hospitalization (HR 1.29; 95\% CI, 1.066-1.553, $P=0.018) .{ }^{16}$ The association between RDW changes and mortality has 
also been shown in another study by Al-Najjar et al. (HR 1.27; 95\% CI, 1.22-1.32, $P<0.001)$ in patients with heart failure $(n=1087$, age range $=64-78)$. In that study, both RDW and NTproBNP predicted mortality and were determined to be independent of each other. ${ }^{17}$ Further evidence demonstrates that a significant positive relationship between RDW and troponin T levels in patients $(n=254$, mean age $=60$ years) with heart failure has also been recorded (odds ratio $[\mathrm{OR}] 1.36 ; 95 \% \mathrm{CI}, 1.08-1.71, P=0.008) .{ }^{18}$

RDW is a useful marker for predicting the risk for developing atherosclerotic diseases, including coronary artery atherosclerosis and coronary artery disease. Changes in RDW are positively associated with increased thickness in the intima-media layers of carotid arteries, which is associated with cardiovascular risks, such as atherosclerosis, cardiovascular death, and myocardial infarction. ${ }^{19}$ In a cohort of elderly patients (age range 60-85 years) with a recent myocardial infarction, but without clinical evidence of heart failure at the time of study, higher levels of RDW even within normal limits have been statistically and clinically associated with increased risk of all-cause mortality, new coronary events, and heart failure. Those in the highest quartile of RDW values had $80 \%$ greater risk of all-cause death than those in the lowest quartile. ${ }^{7}$

RDW is also a strong and independent predictor of death associated with acute coronary syndromes. These include ST-segment elevation myocardial infarction (STEMI), non-STsegment elevation myocardial infarction (NSTEMI), and unstable angina pectoris. For instance, Cavusoglu et al. demonstrated that patients who were referred for a coronary angiography $(n=$ 130 , mean age $=66.6$ years $)$ with the highest tertile of RDW had a 2.7 -fold increase in all-cause mortality compared to the lowest tertile of RDW. ${ }^{20}$ In addition to heart attack, the association between RDW and stroke has also been documented in patients having a history of stroke and 
elevated RDW ( $n=480$, Ó5 years $=64.0 \%$ ) for both increased risk of cardiovascular death and all-cause death. ${ }^{8}$

The relationship between RDW and diabetes mellitus (DM) has also been demonstrated. Among patients with DM, increased RDW levels are associated with higher risk for developing vascular disease, such as nephropathy and other diseases of the blood vessels. ${ }^{11}$ For example, in patients with T2DM ( $n=617$, mean age $=62.6$ years), RDW values in the highest quartile (13.9$24.1 \%$ ) were associated with twice the risk in developing nephropathy and an increased risk in developing other vascular diseases. ${ }^{11}$ The association between elevated RDW and DM is especially concerning as DM has also been connected with fall events in nursing home-dwelling older adults $(n=139$, mean age $=88$ years $)$ as an independent risk factor $($ adjusted HR 4.03; 95\% CI, 1.96-8.28). ${ }^{21}$ Complications associated with DM, such as peripheral and autonomic neuropathy, retinopathy, diabetic foot ulcers, poor glycemic control, or hypoglycemia, may also independently contribute to the risk of falling. ${ }^{21}$

Pancreatitis, hepatic dysfunction, inflammatory bowel disease, and pulmonary disease are also connected with occurrence of elevated RDW. Increased RDW upon hospital admission has been shown to be an independent risk factor for mortality in patients with acute pancreatitis $(n=$ 102, median age $=56.5) .{ }^{13}$ Estimating mortality is important for clinical decision making in prioritizing and implementing treatments during ñearlyò or ñateò phases of disease presentation and in assessing the type of surgery most appropriate for the pancreatitis patient. The physiological mechanism for this association is hypothesized to be related to inflammation. ${ }^{13}$ 


\section{Proposed Mechanisms behind Elevated RDW other than Anemia}

In addition to anemia, chronic, uncontrolled inflammation is believed to play a role in the elevation of RDW. Inflammation may affect RDW by limiting the lifespan of RBCs. RBCs have a high antioxidant capacity and are thought to function as a main ñoxidative sinkò of the body for stopping free radical reactions and transporting reactive oxygen species. ${ }^{19} \mathrm{RBC}$ maturation is also directed by erythropoietin. ${ }^{22}$ There is evidence to suggest that systemic inflammation may blunt the synthesis and activation of erythropoietin. Based on this hypothesis, the combined effects of increased RBC destruction due to systemic inflammation and an insufficient up-regulation of RBC synthesis/maturation may lead to anemia over time. ${ }^{23}$ This theory appears to be supported by limited epidemiological data. Middle-age and elderly adults ( $n=979$, mean age $=63$ years) in the highest quartile of RDW (Ó14.8\%) were also found to have significantly elevated markers of inflammation (high-sensitivity C-reactive protein (hsCRP) mean $=5.5 \mathrm{mg} / \mathrm{L}$, erythrocyte sedimentation rate $(\mathrm{ESR})$ mean $=34 \mathrm{~mm} / \mathrm{h})$ than those in the lowest quartile of RDW (Ò13.1\%). ${ }^{24}$

The presence of systemic inflammation is often characterized by an increased C-reactive protein (CRP) concentration. CRP is a predictor of morbidity and mortality associated with cardiovascular disease. ${ }^{24-29}$ In a study of 366 women (mean age $=59.3$ years), a four-fold increase in cardiovascular events was observed between women with plasma hsCRP in the highest quartile versus those in the lowest quartile. ${ }^{25}$ Moderately elevated CRP levels (>3 $\varepsilon \mathrm{g} / \mathrm{mL}$ ) were associated with frailty after adjustment. Frailty was defined by the presence of three of nine possible measures for frailty in adults aged 65 years and older. ${ }^{30}$ Another study of 1086 middle-aged and elderly men found higher CRP plasma concentration was associated with an increased incidence of myocardial infarction and ischemic stroke. ${ }^{26}$ After adjusting for other 
comorbidities, such as hypercholesterolemia, Type 2 diabetes, hypertension, and family history of premature myocardial infarction, the risk for cardiovascular events among women with high hsCRP remained significantly elevated. ${ }^{25}$ In a separate study of 3845 subjects (median age $=60$ years), the percentage of subjects considered to have elevated hsCRP (> $3 \mathrm{mg} / \mathrm{L}$ ), consistently increased across quartiles of RDW $(P<0.001) .{ }^{24}$ Similarly, the percentage of subjects who had an ESR $>40 \mathrm{~mm} / \mathrm{h}$ also increased across RDW quartiles $(P<0.001) .{ }^{24}$ Since epidemiological studies have shown that increased CRP is associated with increased cardiovascular events, and since patients with elevated CRP may also have increased RDW, it is possible that high RDW may be predictive of cardiovascular events in some patients.

It has also been suggested that elevated RDW is associated with poor health. ${ }^{7}$ In a study using data from NHANES III, middle-age and older adults with congestive heart failure, diabetes, history of heart attack, pulmonary disease, or stroke and elevated RDW were found to experience a higher all-cause mortality rate in the 12-year follow-up period, even in absence of anemia. ${ }^{31}$ Additionally, with each $1 \%$ increase in RDW from baseline, there was a corresponding $22 \%$ increase in mortality risk, and a $37 \%$ increase in mortality risk after adjusting for demographic, behavioral, and biomedical risk factors. ${ }^{31}$ Similar risks were demonstrated in community-dwelling older adults where a $14 \%$ increase in total mortality risk was seen for each $1 \%$ increase in RDW in adults aged $70-79$ years. ${ }^{32}$ To summarize, elevated RDW is associated with increased mortality in middle-aged and elderly patients with chronic comorbidities.

RDW appears to be elevated in the presence of systemic inflammation and a positive correlation has been observed between RDW and other markers of inflammation, such as hsCRP, CRP, and ESR. RDW has also been associated with outcomes such as mortality, risk of clinical outcomes and comorbidities, and also has comparable prognostic power to other estimators of 
outcome. RDW has not been associated with the outcome of fall events, however. Based on the associations of markers of inflammation with the outcomes of mortality and comorbidities, and considering the association of these comorbidities with the outcomes of frailty and falls in older adults, this evidence may validate investigation of the association between RDW and factors of fall events.

\section{Overview and Epidemiology of Falls in Older Adults}

Falls are a leading cause of both fatal and nonfatal injuries in older adults. ${ }^{33}$ One in three adults aged 65 and above living in the United States general population experiences a fall every year. $^{34,35}$ Rubenstein et al. and Fuller have noted the fall rate for older adults living in nursing homes to be two to three times the rate for community-dwelling older adults. ${ }^{36,37}$ Currently, there are over 1.3 million older adults residing in American nursing homes. ${ }^{38}$ An increased fall rate in nursing homes may be partially attributed to the increased frailty of those requiring chronic care as well as increased reporting and documentation of falls that occur in nursing homes. Additionally, mortality from injuries sustained by older adults in nursing homes is disproportionately higher than those living in the community. ${ }^{36}$ For older adults living in nursing homes, one out of every five falls leads to complications that results in death. ${ }^{39}$ There is also a high frequency of recurrent falls among nursing home residents, increasing the likelihood of becoming injured as a result of falling. ${ }^{36}$

For nursing home residents, the causes of falls are related to issues with gait, balance,

weakness, vertigo, or confusion. ${ }^{36,40-42}$ By comparison, community-dwelling older adults more commonly experience falls related to their environment. Increased weakness and poor gait can be traced to many causes, mainly aging and the associated physiologic processes. Chronic 
medical conditions such as cardiovascular disease or pulmonary disease not only decrease muscle and body strength, but may also necessitate prolonged bed rest, which is associated with the deconditioning of muscles. In addition to age-related declines in gait velocity, step height, stride length, reaction time, visual acuity, perception of depth, and increased postural sway, chronic diseases of the lungs, cardiovascular, or musculoskeletal system may also contribute further to these declines and affect gait. ${ }^{36,40-42}$ Impaired equilibrium may affect sense of balance and acquired hemiplegia may contribute to instability during locomotion or transferring. ${ }^{43}$

\section{Consequences of Falls in Older Adults}

Injuries increase the risk of fractures (usually of the hip), lacerations, head trauma, and early death in $20-30 \%$ of cases. ${ }^{44,45}$ Following a fall episode that results in a hip fracture, three major consequences have been observed among older adults: (i) elevated mortality in the first three months following a fall, (ii) a decreased level of functioning, and (iii) the need for costly clinical care and therapy for rehabilitation. ${ }^{46}$ Stevens et al. reported that among non-fatal fall injuries, fractures were present in $35 \%$ of the cases. However, the associated healthcare costs related to non-fatal falls account for $61 \%$ of medical care costs in the U.S. ${ }^{47}$ An older person is more likely to suffer from a fatal fall injury than a younger person. ${ }^{36}$ Falls account for nearly half of all geriatric trauma. Geriatric patients who fell sustained more injuries to the head/neck and pelvic/extremity areas when compared to younger cohorts who experienced falls of similar severity. ${ }^{48}$ Sterling et al. determined that closed-head injury was the most common cause of death from falls in an elderly population. ${ }^{48}$ The direct medical cost of falls was $\$ 30$ billion in 2010, and Rawsky noted that up to $40 \%$ of skilled nursing facility admissions were related to falls. ${ }^{49-51}$ This cost estimate does not include the expense of insurance claims processing, 
additional disabilities adaptations (such as wheelchair ramps) to the home if a patient is able to return after therapy, home care aides, and lost wages if the older adult had been employed. ${ }^{47}$ Women, who comprise $58 \%$ of the older adult population and live longer than men on average, had medical treatment costs for falls that were 2 to 3 times higher than men in all treatment settings, which included hospital, emergency department, and outpatient visits. ${ }^{47,52}$ Women may be disproportionately affected because they may be more likely to have osteoporosis and musculoskeletal weakness than older men. ${ }^{47,53}$

Falls also result in decreased quality of life. Even when not injured, many people who fall develop a fear of falling and ñpost-fall anxiety syndrome. ơ $^{36,54,55}$ As older adults lose confidence in their ability to ambulate safely, this can cause them to limit their activities, contributing to poor mobility, myodynamia, and decreased physical fitness, which subsequently increase the actual risk of falling. ${ }^{56}$ Women are more than twice as likely as men to develop a fear of falling. Walking and bathing have the most significant relationship with fear of falling. ${ }^{43}$ A fear of falling can promote depression that co-occurs with anxiety, a sense of helplessness, and social isolation. ${ }^{40}$ Benzodiazepines, used to treat anxiety in elderly patients, may cause cognitive impairment and subsequently increase the likelihood of falling. It is also suspected that these anxiolytics may antagonize the effects of antidepressant medications, causing delayed or poor response to the intervention and permit continued depression. ${ }^{57}$ Depression and cognitive impairment from benzodiazepine treatment may combine to contribute to a fear of falling and decreased quality of life. Fear of falling has been significantly associated with at least one debility in the Instrumental Activities of Daily Living (IADL) $(P=0.0001) .{ }^{58}$ A significant association between fear of falling and one IADL impairment remained after logistic regression. 
Subjects who had at least one IADL incapacity also were more likely to have chronic comorbidities such as heart disease, diabetes, stroke, or depression. ${ }^{58}$

\section{Assessment of Fall Risk}

There are several assessment tools that can be used to estimate the risk of falling. These screening tools include assessment of age, ability to complete activities of daily living (ADL), deficits in gait and balance, muscle weakness, cognitive impairments, use of certain medications, depression, arthritis, and vision or other sensory deficits. ${ }^{59,60}$ However, many of these tools have weaknesses. Many include subjective measures that rely on the older adultôs memory or cognition, such as remembering how many falls were experienced over a time period, and judging what constitutes a fall. ${ }^{61,62}$ The Centers for Medicare and Medicaid Servicesô(CMS) State Operations Manual describes a fall as ñunintentionally coming to rest on the ground, floor, or other lower level. $0^{63}$ This includes falling on to or out of chairs, beds, or equipment used for therapy or transfer. It also includes any incident in which a person is found on the floor when there is no evidence to indicate an event other than a fall took place. Additionally, when a slip or trip occurs and physical injury results, this also constitutes a fall. ${ }^{64}$ Subjectivity on the part of the older adult when providing medical history can introduce recall bias, particularly in a population that is already at risk for memory and cognition impairments. Additionally, some assessment components depend on the assessorô ability to make subjective evaluations about the patient $\hat{Q}$ level of cooperation, insight, ability, and judgment, which may be difficult to determine during initial assessments. ${ }^{65}$ There are many types of fall assessment tools available. Not all practice settings use assessment tools that are evidence-based, favoring their own in-house derived assessment instead. Some evidence-based and validated models are described in Table 1. 


\section{Deficiencies in Fall Risk Assessment Tools}

The CMS Outcome and Information Set (OASIS-C) mandates that a ñstandardized, validated, multi-factorò falls assessment tool be used in the evaluation of residents at risk to fall. $^{66,67}$ It is not mandated which tool should be used, but the tool needs to have been tested using subjects similar to the subject to be tested, and the tool needs to have a standard response scale. ${ }^{66,67}$ Suggested factors for the tool to address include medication use, history of falls, impairment of mobility or transferring, cognitive impairment, frequency of toileting, and environmental hazards. ${ }^{66,67}$ Alternatively, the facility may ask the subject to complete a performance-based test plus the assessment of one additional risk factor. ${ }^{67}$

While many factors contribute to falls risk and are useful to assess, falls risk assessment tools may still leave care staff unclear regarding a patient $\hat{Q}$ risk to fall. There are numerous tools for incorporating a falls risk assessment into a particular setting or practice; however, assessments have not been thoroughly studied. Some assessment tools are accompanied by data to gauge their effectiveness, but this may be limited to a single study, or a study with a small number of participants. Falls risk assessment is also not standardized across settings, such as between acute care and long-term care for similar populations. Few efforts to even validate or assess them for reliability in multiple settings have been made. ${ }^{68,69}$ While it may not be appropriate to recommend one assessment as fitting for all settings, the evidence that is available about these tools is often confined to a single practice setting. ${ }^{68,69,70}$ It is not clear how some tools were derived and scoring appears arbitrary in multiple cases. Further, even though tools that have been studied several times may have a high specificity to assure staff a patient is at little risk to fall, the tools may also have low sensitivity, which would not detect other patients 
who were actually at increased risk to fall. ${ }^{68}$ Additionally, only some assessment tools have been validated to predict falls specifically. ${ }^{71}$ The paucity of research on the predictive ability of fall assessment tools may be reflected in that their main purpose, according to some sources, is not to predict risk, but rather to identify the areas where clinical intervention is deemed likely to prevent falls and is required by ethical guidelines or a regulatory agency. ${ }^{69,71}$

If a patient is unable to complete a physical task, this may limit the usefulness of the assessment tool. ${ }^{72,73}$ In a study attempting to determine which test is the best falls assessment tool, researchers found that only about half of ambulatory participants were able to complete a physical assessment of falls risk. Of the eight assessment tools included in that study, none of them were found to have adequate predictive ability. ${ }^{72}$ If a patient cannot complete the test due to cognitive impairment such as in impaired orientation, confusion, or difficulty understanding the test, this incapability is one of the most significant factors affecting risk to fall in the elderly. $^{74}$

Some of the validated assessment tools may also contain procedures which could be considered to be dangerous, such as requiring the subject to stand with eyes closed for 1 minute, balancing on foot, or maintaining balance after receiving a ñnudge.ò Other assessments advise staff to be ready to catch a participant should he or she begin to fall (Table 1). While these assessments may have been tested with older adults, they still may not be practical or appropriate to use in any older adult setting.

Additionally, there may be variability in the interpretation of instructions for a specific risk assessment task among clinical care staff members. One member may score completion of a single repetition in a physical task differently than another member, resulting in inter-observer variability. The inaccuracy and inconsistency within assessments are further confounded by 
inter-facility variance. It may also be difficult to grade a participantô status and standing posture due to contractures, kyphosis, or other abnormalities. Facilities may also develop their own inhouse assessment tools, which are attempts to meet the needs of a particular facility. However, this may not be efficient as the scores of these assessments would not be comparable to those in other facilities. This need for comparison is especially necessary if a patient is transferred from one facility to another. ${ }^{71}$ Additionally, tools developed in-house may not have been adequately validated, leaving their accuracy unknown. Due to the subjectivity, limited use of some tools in some populations, need for expedient assessment, and limited data available on the currently used assessment tools for fall risk, there is a need for more objective assessment tools.

Expediency is also necessary in fall assessment. In acute and chronic practice settings clinical staff often are required to perform fall assessments routinely for many patients and repetitively for long-term patients over time. Often, clinical staff members are governed by strict time constraints in order to complete assessments. If staff members are required to perform a lengthy assessment, some may not complete this step. ${ }^{70}$ Therefore, assessment components need to be easily implemented and quickly obtained. However, because of the high frequency of use in some settings, some assessments may be too brief, overlooking important aspects of the patientô health. In a study of four previously-studied fall risk assessment tools, three were found to require an amount of time in excess of 6 minutes to complete, while the fourth tool had the lowest sensitivity. ${ }^{73}$ Other assessments recommend reserving more than 10 minutes to complete the evaluation (Table 1). Additionally, some evidence indicates that staffôs perception of a patientôs risk to fall was superior in predicting falls to some of the commonly used and validated falls assessment tools. ${ }^{75-77}$ This perception may increase the attraction of foregoing time-consuming assessment tools altogether in clinical practice. 
With the lack of adequately studied risk assessment tools, the significant resources and staff commitment to implement common standardized tools, and the CMS mandate that a standardized tool is necessary, alternatives to lengthy assessments need to be identified for additional research and standardization. ${ }^{66,67,71,73}$ One solution may be to identify laboratory values, such as RDW, that can assist in identifying those at increased risk to fall. Laboratory values are more expedient to read than performing a falls assessment, and they are less subjective than interpreting medical history. Because of the extensive barriers to using the currently available and partially-validated fall assessment tools, examination of the literature on independent fall risk factors is essential.

\section{Factors That Increase Fall Risk}

There are several factors that are commonly addressed in assessments for risk to fall. Some risk factors are repeatedly found to be common in many different assessments. However, factors that effectively predict falls may not necessarily be those that cause them. Factors commonly found on assessments for risk to fall include those which evaluate mobility impairment, weight, urinary incontinence or required assistance with toileting, history of falls, prescription of medications that have sedative or hypnotic effects, impaired judgment/cognition, and poor vision. ${ }^{6}$

\section{Mobility Impairment}

Mobility impairment includes components such as gait, balance, stability, and the use of assistive devices. Poor gait can include reduced stride, slowing, widening of base support, reduced step height, increased time when both feet are in contact with the floor, and moving the feet in an arc with soles parallel to the ground rather than a straight line while stepping 
forward. ${ }^{16,78}$ Gait rhythm, timing of the stride cycle, and consistency of the cycleð between left and right feet, and within the same foot $ठ$ are assessed. ${ }^{78}$ Impairments to gait can be categorized into difficulties with muscle strength, joint mobility, pain, sensation, spasticity, neurologic central processing, or a combination of any of these. ${ }^{36}$ Gait cycle durationð also known as stride time or intervalठ reflects walking rhythm, which is strongly correlated with functional status in older adults. Variations in stride time are also associated with success on performance-based tests of function, which can predict certain clinical outcomes, such as nursing home admission and morbidity. ${ }^{79}$ Stride time can be discussed in regards to the absolute size of the variation, and how it has changed from previous strides. ${ }^{79}$ In a randomized controlled trial aiming to assess the effect of exercise on gait instability in 67 adults over 70 years old, those that reported two or more falls in the previous year were found to have significantly more variation in stride time $(P$ $=0.02) .{ }^{79}$ Other factors that influence gait stability include health-related quality of life and neuropsychological status. ${ }^{79}$ However, the etiology of gait instability in older adults stems from several co-existing factors. ${ }^{79}$ In adults over 65 years of age, having an unsteady gait was found to increase the risk of falling significantly (OR 2.1, 95\% CI, 1.2-3.64, $P=0.04) .{ }^{68}$ Additionally, gait status and changes in gait may be difficult to assess over time. In a study of 85 adults recently admitted to a geriatric ward with a mean age 75.8 years, evaluation of the Timed-Upand-Go (TUG) test, Berg Balance Score, and Tinettiôs Gait and Balance Test revealed that the TUG was the most sensitive to changes in gait over time with $93 \%$ sensitivity. ${ }^{80}$ Results of these tests were compared with gait analysis, which included a 5.6-meter electronic walkway with which three experts in gait disorders (a physiotherapist, neurologist, and a geriatrician) evaluated film of subjectsômovement on the walkway. However, after follow-up, measures indicated there was high intra-individual variability, even within the group considered to be ñstable. $0^{80}$ In that 
study, the median time to complete the TUG was 19.3 seconds. ${ }^{80}$ This is well above the 13.5 second cutoff point, indicating many subjects would be considered at risk to fall despite correctly applying the TUG for use in ñfrail elderly personsò as is recommended in other research. ${ }^{80,81}$ These results highlight challenges faced not only by researchers, but clinicians working to assess gait in older adults in practice.

The aging process is associated with weakness in the lower extremities. Strength in the ankle, knee, and hip has been shown to decline by up to approximately $3 \%$ per year beginning after age fifty. ${ }^{82}$ This occurs with a reduction in the ability to generate force. ${ }^{82}$ Lower extremity weakness contributes to decreased ability to generate force and results in a deterioration of balance. In a review of multiple studies, lower extremity weakness was significantly associated with any fall (combined OR 1.76; 95\% CI, 1.31-2.37), as well as with recurrent falls (OR 3.06; 95\% CI, 1.86-5.04). ${ }^{83}$ Force-generating capacity of the ankles has been found to predict patient scores on the Berg Balance Scale, Functional Reach Test, and the TUG test. Specifically, the force of the ankle dorsiflexors demonstrated the best use of this application as a predictor of falls in older adults. ${ }^{84}$ Some results indicate that certain exercises may be able to improve the strength of affected muscle groups and reduce fall risk. Exercise improves the ability to rise from a chair, climb stairs, stoop, transfer, and increase gait speed. ${ }^{85}$ Strengthening of ankle dorsal and plantar flexors has resulted in improvements in the TUG test in as little as 12 weeks. Similarly, scores in timed distance walks were also enhanced with exercise of the knee extensors and flexors. ${ }^{86}$ Strength of the hip has also been shown to be associated with risk of falling. Two sites within the same study both demonstrated significantly increased risk of falling in subjects determined to have weak hip strength (OR 8.36; 95\% CI, 2.17-25.79, $P<0.001$, and OR 10.33; 95\% CI, 2.6440.36, $P<0.001) .{ }^{87}$ Further research is needed regarding identification of which muscle groups 
that weakness significantly impacts to increase risk of falling and the degree of strength required in these groups to prevent falling.

\section{$\underline{\text { Body Weight }}$}

Body weight changes, particularly weight loss, can affect risk of falling. ${ }^{88}$ A weight, and subsequently, a Body Mass Index (BMI) that is outside a normal range $\left(18.5-24.9 \mathrm{~kg} / \mathrm{m}^{2}\right)$ can influence other factors relating to falls risk. ${ }^{89}$ Obesity may affect balance, ability to recover following a threat to balance, strain ankle support, impact posture, and ability to recover following an injury. ${ }^{90}$ Those who are overweight $\left(\mathrm{Q}^{2} \mathrm{~kg} / \mathrm{m}^{2}\right)$ and having an android adiposity distribution tend to be associated with a higher risk of falling than those of a normal BMI range $($ OR $5.35 ; 95 \%$ CI, 1.75-16.39; $P=0.003) .{ }^{89}$ Obese subjects demonstrate increased rates at which their center of mass shifts compared to non-obese subjects and tend to move their entire body forward while performing balance tests. ${ }^{90}$ Postmenopausal women are likely to experience changes to their body composition, such as an increase in weight and a shift from gynoid to android adipose distribution. ${ }^{89}$ In women who were at least 65 years of age, the odds of recurrent falls were increased across all weight categories in frailty (underweight OR 2.54, 95\% CI, 0.47-13.87; normal weight OR 3.61, 95\% CI, 2.51-5.17; overweight OR 1.95, 95\% CI, 1.322.88; obese OR 1.68, 95\% CI, 1.05-2.68). ${ }^{91}$ Weight stability in an older adult may not afford a decrease for this risk of falling either. Sarcopenia occurs with aging. As muscle mass decreases, there is a simultaneous increase in adipose tissue in many older adults, masking weight changes. In independently-living, healthy older adult males (mean age $72.9 \pm 5.5$ years), longitudinal measures of total skeletal muscle mass indicated a significant decrease of $0.8 \pm 1.2 \mathrm{~kg}(P=$ 0.002) over a five-year study, and females with similar characteristics (mean age $70.2 \pm 7.8$ years) experienced a decrease in total skeletal muscle mass of $0.4 \pm 1.2 \mathrm{~kg}(P=0.006)$ over the 
same time period. ${ }^{92}$ These changes occurred while neither men nor women had statistically significant changes in weight. ${ }^{92}$ In men, fat mass increased significantly. ${ }^{92}$ This loss of muscle and simultaneous gain of fat mass in weight neutral older adults may affect balance and mobility, since the decrease in skeletal muscle was significant in the lower extremities for both men $(-0.7$ $\pm 0.8 \mathrm{~kg}, P=0.001)$ and women $(-0.3 \pm 0.8 \mathrm{~kg}, P=0.005) .{ }^{92}$ Being underweight may also increase fall risk. Decreases in body weight due to bone mineral density loss, decreased dietary calcium intake, and decreased lower extremity strength were found to significantly support an increased falls risk in elderly men. ${ }^{93}$ In older adults ( $n=722$, age Ó65 years) a BMI of Ò 9 $\mathrm{kg} / \mathrm{m}^{2}$ was found to be associated with falls in both men (OR 5.4, 95\% CI, 1.7-22.0) and women (OR 3.7, 95\% CI, 1.7-8.5). ${ }^{94}$ In community-dwelling men Ó65 years of age, those with a BMI of $<25 \mathrm{~kg} / \mathrm{m}^{2}$ experienced fall events an average of 3.9 times in a two-year study period. ${ }^{95}$ Honeycutt et al. showed that having a BMI of $<25 \mathrm{~kg} / \mathrm{m}^{2}$ was a factor that was noted to be significantly different between the subjects who fell and those who did not fall $(\mathrm{P}<0.05) .{ }^{95}$ In this study, a BMI of $<25 \mathrm{~kg} / \mathrm{m}^{2}$ was considered to be ñow, òcompared to ñmoderateò (25-27 $\left.\mathrm{kg} / \mathrm{m}^{2}\right)$ and f̃̃ighò $\left(>27 \mathrm{~kg} / \mathrm{m}^{2}\right) .{ }^{95}$ The association between a BMI of $<25 \mathrm{~kg} / \mathrm{m}^{2}$ and fall risk is thought to be related to poor health or nutritional status, decreased amount of soft tissueð which can absorb the energy of a fall,ठ and poor quality of the available soft tissue in general. ${ }^{95}$

\section{$\underline{\text { Urinary Incontinence }}$}

Urinary incontinence or the need for assistance when toileting is associated with falls in older adults. Between $20-50 \%$ of falls are related to toileting activities. ${ }^{96}$ Additionally, urinary incontinence in community-dwelling elderly aged Ó65 years $(n=1285)$ was reported to be significantly associated with any fall (Ól) and recurrent (Ó) falls with OR = 1.8 (95\% CI, 1.42.4) and $\mathrm{OR}=2.3(95 \% \mathrm{CI}, 1.6-3.2)$, respectively. ${ }^{35}$ Approximately $20-30 \%$ of men and $30-40 \%$ 
of women over the age of 64 experience urinary incontinence. ${ }^{96,97}$ Older adults may not seek medical help for incontinence for a variety of reasons. Thinking the problem will go away on its own, accepting it as part of the aging process, or not considering it a medical problem that is worthy enough to seek medical help are common reasons for lack of intervention. ${ }^{97}$ It is unclear whether stress or urge incontinence is likely related to fall events. ${ }^{97,} 98$ However, in a review of several studies, mixed incontinence types were found to be associated with higher odds of falling in older adults (OR 1.92; 95\% CI, 1.69-2.18) compared to either stress or urge incontinence. ${ }^{97}$ Additionally, nocturia may negatively impact the quality of sleep and quality of life in older adults. ${ }^{97}$ Older adults who experience Ó̉ nocturia episodes per night were approximately twice as likely to also experience dizziness and poor balance in the daytime compared to older adults who had $\mathrm{O} 2$ nocturnal voids per night. ${ }^{99}$ In addition to interrupting sleep cycles, nocturia may increase fall events due to quick changes in body position from lying down to standing up, and potentially poor lighting conditions at night, which can be further compounded by visual impairment. $^{97}$

\section{Impairment of Cognition or Judgment}

Impaired judgment or cognition also contributes to fall risk. In older adults, this commonly manifests as dementia, including Alzheimerô disease or vascular diseases such as stroke. It is believed that cognitive processing may influence balance ability, with standing postural regulation utilizing the same neuron pathways as cognitive spatial processing. In a controlled clinical trial, when visual cues or environmental information on walking surfaces was limited, older adults were required to draw on more attentional resources than younger adults in order to maintain upright posture. ${ }^{100}$ Additionally, older adults have decreased ability to recover postural stability after external perturbation than younger adults because restabilizing posture is 
more attentionally demanding. More attention is also required for dynamic equilibrium tasks rather than for static equilibrium tasks. ${ }^{101}$ In subjects aged Ó65 years $(n=702)$ who were assessed using the Modified Mini Mental State Examination (3MS), those who were at risk for dementia (score <80) had increased risk of falling compared to those who scored $>90$ on the test (HR 2.16; 95\% CI, 1.60-2.91). ${ }^{102}$ Scores on the 3 MS test range $0-100$, and a score of $<80$ has been used to identify subjects/patients who may need further cognition-related screening. ${ }^{102}$ In a study of adults of 60 years or older $(n=109)$ living in nursing home care, those who fell performed worse than those who did not fall on cognitive tests conducted at baseline and at termination of a 6-month study period. ${ }^{103}$ The tests utilized in this study assessed the areas of attention and orientation (RR 2.00; 95\% CI, 1.32-3.03; $P<0.001$ ), memory (RR 1.69; 95\% CI, $1.17-2.45 ; P=0.005)$, and fluency (RR $1.69 ; 95 \% \mathrm{CI}, 1.17-2.45 ; P=0.005) .{ }^{103}$ Impaired memory may contribute to fall events by interfering with the ability to recall safety strategies, such as remembering to use an assistive device. ${ }^{103}$ Use of the assistive device has its own cognitive demands as well. Over $87 \%$ of fall injuries associated with assistive devices involve the use of walkers in adults aged Ó65 years. ${ }^{104}$

\section{$\underline{\text { Vision Status }}$}

Poor vision is an independent risk factor for falls, and is associated with one-quarter to half of falls. ${ }^{105}$ Poor visual acuity has been found to double the risk of falling with an adjusted $\mathrm{OR}=2.3(95 \% \mathrm{CI}, 1.18-4.63){ }^{106}$ The main components of vision that affect risk to fall are depth perception, contrast sensitivity, and visual acuity. These functions are also closely related, meaning that a patient is likely to have decreased performance on all of them even if only one function is known to be affected. In dementia, a loss of visual fixation occurs. ${ }^{105}$ This may be one way decreased visual functioning contributes to risk of falling. Additional challenges with 
vision in older adults include cataracts, glaucoma, macular degeneration, diabetic retinopathy, and refractive errors. ${ }^{105}$ Some evidence states that reduced contrast sensitivity has been associated with recurrent falls (HR 2.09; 95\% CI, 1.14-3.10; $P<0.001) .{ }^{107}$ Further, difficulty recognizing faces was associated with fractures related to falls (HR 3.1, 95\% CI, 1.65-5.82; $P<$ 0.001) ${ }^{107}$ However, it is difficult to separate this from other factors that influence facial recognition, such as the environment and memory. ${ }^{107}$ Older adults who require corrective lenses may also have outdated prescriptions or forget/refuse to wear them. ${ }^{108}$ Corrective lenses themselves may be problematic as wearers of multifocal lenses often look through the lowest level of the lenses to see obstacles at their feet. The lowest level of the lens is calibrated for distances of 0.6 meters, resulting in blurring at floor-level. Older adults who wear multifocal lenses were shown to have significantly greater likelihood of falling than those who wear nonmultifocal lenses (OR 2.29; 95\% CI, 1.06-4.92; $P=0.028) .{ }^{109}$

\section{Vitamin D}

Some evidence suggests that low levels of micronutrients may influence falls in an older adult population. For instance, in a meta-analysis of five randomized controlled trials ( $n=1237$, mean age $=70$ years), vitamin D supplementation (400 IU per day to 300,000 IU once in 6 months) has been shown to reduce the risk of falls in ambulatory and institutionalized older adults by over $20 \%{ }^{110}$ In a study examining the effects of vitamin D supplementation in elderly patients ( $n=124$, age range 68-104 years) living in a nursing home, those receiving the highest dose of vitamin D supplementation (800 IU) for the five-month study period had a rate of falls that was $72 \%$ lower than the placebo group. ${ }^{111}$ Additionally, the adjusted risk of falling in the $800 \mathrm{IU}$ group had a rate ratio $=0.28(95 \% \mathrm{CI}, 0.10-0.75) .{ }^{111}$ Vitamin $\mathrm{D}$ is thought to promote

healthy bone mineral density, but may also improve muscle strength. ${ }^{110,112}$ Vitamin D receptors 
in skeletal muscle promote protein synthesis when activated. ${ }^{113}$ These proteins act to differentiate and proliferate muscle fibers, and support calcium influx in muscle activation. ${ }^{113}$ Adequate vitamin D status can help to reduce secondary hyperparathyroidism, reducing osteoporosis and loss of bone mineral density. ${ }^{111,112}$ Patients with hypovitaminosis D may be more likely to benefit from vitamin D supplementation. Vitamin D supplementation may reduce the risk of falling, fall rates, and injurious falls in older adults. ${ }^{111,114-116}$

\section{Medication Use as a Risk Factor for Fall Events}

Medication use may impair a variety of functions or systems within the older adult user, affecting alertness, balance, or muscle control. ${ }^{117,118}$ Certain classes of medications have been associated with increased fall risk. These include antihypertensive agents, diuretics, sedatives and hypnotics such as benzodiazepines, antipsychotics, antidepressants, and non-steroidal antiinflammatory drugs. ${ }^{119}$ Moreover, polypharmacy has been shown to be a risk factor for falls in older adults, particularly when the concurrent drug regimen includes multiple medications that have been established to increase risk of falling. ${ }^{117}$

When multiple medications are used, it is important to evaluate the needs and appropriateness of each of the drugs for a specific patient. ${ }^{120}$ One approach in identifying potentially inappropriate medications (PIMs) in elderly patients is to use the Beers Criteria. ${ }^{120,121}$ The Beers Criteria were designed to assist clinicians in optimizing medication use for older adults residing in nursing homes and reduce adverse drug events. ${ }^{121}$

Medications which act on the central nervous system are commonly implicated in fall events. $^{117,118}$ Psychotropic medications such as antidepressants and benzodiazepines act on the central nervous system and are found to be associated with falls in the elderly. ${ }^{122}$ In a study of 
2854 adults with a mean age of 77.2 years, those taking benzodiazepines (OR 1.36, 95\% CI, 1.08-1.71) or any psychotropic medication (OR 1.48, 95\% CI, 1.09-2.02) experienced an increased risk of falling compared to subjects who were not taking either of those. ${ }^{123}$ The degree to how much risk is added may vary by medication. Ziere et al. found that hypnotic medications and anxiolytic medications were associated with increased risk of falling with an adjusted OR of 1.6 (95\% CI, 1.1-2.1) and 1.3 (95\% CI, 1.0-1.9), respectively. ${ }^{117}$ This adjustment considered comorbid conditions, disability, age, and gender. ${ }^{117}$

Antidepressants have been identified to have a significant association with falling in older adults (OR 1.68; 95\% CrI, 1.47-1.91). ${ }^{119}$ For tricyclic antidepressants (TCAs), evidence suggests that the increased risk associated with use of these medications and falls or injuries in older adults ranges from 50 to $200 \%$ among nursing home residents. ${ }^{124}$ The mechanism by which antidepressants contribute to falls is not well understood. ${ }^{125}$ A likely explanation is the side effect profile of TCAs which may include sedation, impaired psychomotor function, and orthostatic hypotension. ${ }^{120}$ Some studies suggest that the incidence of falls for those using TCAs is different than the rate of falls of those who use selective serotonin-reuptake inhibitors (SSRIs), as SSRIs are not expected to affect the autonomic nervous system the way TCAs would. ${ }^{124}$ Compared to non-users of antidepressants, new users (no previous antidepressant use in the last 90 days) experienced more falls with an adjusted rate ratio $=2.0(95 \% \mathrm{CI}, 1.8-2.2)$ for TCAs and SSRIs (adjusted rate ratio $=1.8 ; 95 \%$ CI, 1.6-2.0) in nursing home subjects Ó65 years of age. ${ }^{124}$ Benzodiazepines have also been found to be associated with fall events. ${ }^{34,125}$ Benzodiazepines are used as anxiolytics, anticonvulsants, muscle relaxants, and sleep aids. ${ }^{126}$ Their use in the elderly may lead to daytime sedation, confusion, cognitive deficits, ataxia, diplopia, vertigo, and falls, and increases the risk for adverse medication reactions in the older 
adult. $^{127,128}$ Whether short- or long-acting benzodiazepines are used may not be as important as the doses in precipitating falls. ${ }^{120,123}$ Benzodiazepines may be appropriate for patients with some conditions, but limiting or tapering their use in the elderly is generally recommended. ${ }^{120,128}$ However, Pariente et al. noted that $80 \%$ of older adults using these medications had been doing so for more than 2 years. ${ }^{128}$ In community-dwelling older adults aged 65 years and older $(n=$ 1285), Tromp et al. found the use of benzodiazepines to be associated with increased risk of falling with an OR of $1.6(95 \% \mathrm{CI}, 1.1-2.2) .^{34}$

Further evidence suggests that initiating or changing a psychotropic medication regimen of any typeð including antidepressants, benzodiazepines, or antipsychoticsð is likely to yield an increased risk of falls. ${ }^{125}$ Echt et al. evaluated changes in psychotropic medications in older adults residing in nursing homes. A change in medication was defined as a new prescription (one that had not been used in the previous 90 days), changing drugs within the same class of medications, or an increase in dosage. ${ }^{125}$ There was a significant difference $(P<0.001)$ in the proportion of residents who experienced Ó falls following a change in psychotropic medication $(41.0 \%)$ compared to those who did not have a change in psychotropic medication $(22.5 \%) .{ }^{125}$ However, it is difficult to separate the effects of the medication from progression of medical conditions in the elderly adult population. The association between fall events and medication use may be confounded by other physiological processes, such as worsening of dementia or physical decline. ${ }^{123,125}$

Medications used to treat cardiovascular diseases may also increase fall episodes. Associations between falls and the use of vasodilators, digoxin, and diuretics (including potassium-sparing agents) have been reported as well. ${ }^{129,130}$ 
Considering these individual risk factors for falls along with the associations of RDW with morbidity and mortality risks justifies investigating the associations between RDW and the fall risk factors. These results may provide support for the potential clinical use of RDW in the assessment for risk to fall in older adults. 


\section{Background and Study Goal}

Red-blood cell distribution width (RDW) is part of the Complete Blood Count (CBC) laboratory panel and is often used to confirm the presence of anemia in conjunction with other laboratory measurements. RDW has been shown to have independent predictive ability of

mortality, clinical outcomes, measures of physiologic risks, and comorbidities. ${ }^{7,8,11,16-21}$

Surrogate markers of systemic inflammation, such as hsCRP, CRP, and ESR, have also been associated with the outcomes of mortality and comorbidities including cardiovascular disease, heart attack, and stroke. Some of these comorbidities have been associated with the outcomes of frailty and falls in older adults. RDW has been associated with the risk of cardiovascular disease, myocyte death, the risk of developing nephropathy or other vascular diseases, and has been shown to have similar prognostic power to other estimators of outcome. ${ }^{5-7,21,32}$ Chronic disease impairs other systems, such as the nervous system, vision, mechanisms related to blood pressure, and also may affect the survival and maturation of RBCs, which may promote increased RBC production, contributing to an elevated RDW level. ${ }^{6,11,21,133,134}$ The presence of certain chronic diseases, such as cardiovascular disease, diabetes, and pulmonary disease, may increase the risk to fall in elderly subjects. ${ }^{131,132}$

The primary purpose of the study was to determine the cross-sectional association between RDW and the number of falls among older adults living in a skilled nursing facility. The hypothesis was that older adults who have a high occurrence of falls will have elevated RDW above normal limits, compared with older adults who have a low number of falls. The sub-aim of this cross-sectional evaluation was to assess the association between RDW and correlates of falls at baseline. These included weight, BMI, medication use, mobility impairment, vision impairment, and facility falls risk assessment scores. The hypothesis 
regarding correlates of falls is that older adults who are at a higher risk of falling according to these measures will have elevated RDW above normal limits, compared with older adults who are low risk of falling according to the correlate measures.

The secondary aim of the study was to examine the longitudinal association between RDW and occurrence of falls over time. We hypothesize that older adults who have increased falls over the course of one year also have elevated RDW values above normal limits, compared with older adults who have a low number of falls over the same time period. The longitudinal sub-aim was to assess the association between correlates of fall risk with RDW values over the same one year time period. These correlates of falls included weight, BMI, medication use, mobility impairment, vision impairment, and facility falls risk score. Older adults who are at higher risk of falling according to correlate measures are hypothesized to have greater RDW values beyond normal limits over time, compared to older adults who are not at risk of falling according to correlate measures.

\section{Methods}

\section{Study Design}

This study design used a retrospective review of patient medical records of patients in long-term nursing care at Foss Home, Seattle, WA from April 2013 to March 2014. Elderly patients who had lived in the facility for at least one year were eligible to be included in the final review of resident records. One yearôs worth of data were collected and organized by quarterly time periods. If several measures of the same type of sample were available, those closest to the quarterly review date were collected. The study was approved by the University of Washington Human Subjects Division/Institutional Review Board. 


\section{Demographic and Clinical Data Collection}

Data were collected from medical records and electronic patient assessments. Electronic data were obtained from Minimum Data Set (MDS) assessments via PointClickCare software and contained documentation of falls occurrence, laboratory values, medical diagnoses, functional status, medications, and anthropometrics. One yearôs worth of data from the MDS included three ñquarterlyò assessments and a more in-depth ñannualò assessment in lieu of a quarterly assessment for that time period. Collected data were entered into an Excel spreadsheet for analysis.

The medical diagnosis list was the source from which the comorbidities were recorded. Smoking (never, current, former), education level (Ò12 years, >12 years), resident living unit, and payment (private pay, other payment method) statuses were categorically recorded. BMI was calculated as $\mathrm{kg} / \mathrm{m}^{2} .^{5}$

Vision impairment and mobility status were recorded. Vision status information was gathered from Section B1000 and consisted of the following categories: adequate, impaired, moderately impaired, and highly impaired. Mobility status information was gathered from Section G0110, item E: Locomotion on unit, and was categorized as independent, supervision, limited assistance, extensive assistance, and total dependence. For degree of vision and mobility impairment, the most recent measure was used.

Additionally, in-house facility fall assessment rubric scores were collected from quarterly data and used to assess comparisons between RDW and facility falls score. Other factors that may affect fall status were recorded (abnormal posture, debility diagnosis, wandering behavior,

and hemi-/quadriplegia). ${ }^{40,83,135}$ Medications as documented in the medication administration 
records from the most recent quarterly time point were collected. Medication use as a risk factor for falling was assessed as the presence of polypharmacy. The CMS guidelines and criteria from previous studies were used to determine polypharmacy. ${ }^{63,136,137}$ Laboratory measures that were collected included values from the $\mathrm{CBC}$ and iron panel.

\section{Statistical Analysis}

Descriptive statistics summarized the results and were expressed as mean values \pm standard deviation (SD) or presented as $n(\%)$. Weight, BMI, and facility fall assessment scores were divided into quintiles and examined continuously for data analysis.

Longitudinal changes in data values were assessed by comparing the most recent data collection point to the oldest collected quarterly set of data. For continuous variables the most recent data were subtracted from the oldest data. Weight $(\mathrm{kg})$ percent change was examined as Ól0\% change over the most recent 6 months, and as a change of $>5 \mathrm{~kg}$. BMI was evaluated as a change of $>3 \mathrm{~kg} / \mathrm{m}^{2}$. For changes in categorical variables (vision and mobility status), the movement between category options was assessed. Functional declines were indicated by negative values, while functional improvements were indicated by positive values. Additionally, quintiles of continuous facility falls scores were examined.

Mono- and multivariate logistic regression was performed and included average RDW, degree of vision and mobility impairments, average weight, average BMI, polypharmacy, and average facility falls score. Evaluations using an unpaired Studentôs $t$-test were made to examine whether a difference in RDW values was seen between comparable subgroups. A $P$-value of ǓÒ 0.05 was considered statistically significant. All analyses were performed with Stata/MP version 13.1 (StataCorp LP, College Station, Texas). 


\section{Results}

A total of 151 residents were initially reviewed for inclusion in the study (Figure 1). Of those, 59 residents were excluded as they had $<1$ year of history in the facility. The remaining 92 residents were included in the final analysis of quarterly data (Figure 2). The majority of the subjects were White women (71.7\%). The leading comorbidities (Table 2) of the study cohort included digestive impairment ${ }^{\grave{A}}(n=68)$, dementia $(n=67)$, depression $(n=66)$, hypertension $(n$ $=64)$, and cardiovascular disease $(n=61)$.

Mean values represent the quarterly measures of variables for the sample as a whole, and are also detailed according to subjects who did $(n=38)$ and did not $(n=54)$ fall in Table 3. RDW ranged from $12-25.2 \%$, and had a mean change of $1.01 \pm 1.49 \%$ among the four quarters. Weight ranged from $38.64-134.55 \mathrm{~kg}$, and had a mean change of $4.62 \pm 3.74 \mathrm{~kg}$ among the four quarters. BMI ranged from $14.18-45.1 \mathrm{~kg} / \mathrm{m}^{2}$, and had a mean change of $1.72 \pm 1.36 \mathrm{~kg} / \mathrm{m}^{2}$ among the four quarters. Facility fall assessment scores ranged from 9-28 points, and had a mean change of $2.45 \pm 2.55$ among the four quarters. Fall events ranged from $0-13$ events, and had a mean change of $0.25 \pm 0.53$ events among the four quarters. Since the mean \pm SD change from quarter to quarter for these continuous variables was determined to be minimal, average values were used in calculations and representation in figures.

\section{Cross-sectional Analyses}

Comparison of RDW in Subjects Who Did and Did Not Fall

\footnotetext{
${ }_{\grave{A}}$ The leading conditions of ñdigestive impairmentò included diverticulitis, diverticulosis, peptic ulcer, cholelithiasis, gastroesophageal reflux disease, oropharyngeal phase dysphagia, and pharyngoesophageal phase dysphagia.
} 
The comparison of average RDW values between subjects who did and did not experience fall events during the study (Figure 3 ) revealed no significant difference $(P=0.12)$. The mean and median average RDW percentage for those who fell were $14.31 \%$ and $13.9 \%$, respectively, while the mean and median average RDW percentage for those who did not fall were $14.86 \%$ and $14.65 \%$, respectively. There were no significant differences in average RDW values between subjects who fell compared to subjects who did not fall in subgroup analysis by age, sex, race, education, smoking status, payment type, or the comorbidities assessed.

\section{Evaluation of RDW Values Amongst Correlates of Falls}

Specific Aim 1b addressed the correlates of falls in a cross-sectional manner. Figure 4 displays the average RDW by quintiles of average weight $(\mathrm{kg})$. The average weight of subjects in the $5^{\text {th }}$ weight (highest) quintile was significantly different from quintiles $1-4$ of weight $(P=$ 0.02). The RDW value for subjects in the $5^{\text {th }}$ weight quintile was $15.39 \%$, while the RDW value for subjects in the lower four quintiles was $14.43 \%$. The comparison of the lowest $\left(1^{\text {st }}\right)$ weight quintile to the upper four $\left(2^{\text {nd }}-5^{\text {th }}\right)$ weight quintiles yielded no significant differences between these values.

There was also a significant difference noted with the evaluation of average RDW by average facility falls score. The assessment scoring rubric indicated that a score of 10 or more points indicated a subject should be considered to be at risk to fall (Figure 5). According to this, $98 \%$ of the sample met the criteria for being at risk to fall. There were no significant differences at the 10-point threshold. The falls score mean and median was 18 points. Examining the average RDW values by subjects who had more than 18 points compared to those who had 18 or fewer points indicated there was a statistically significant difference between these two groups $(P=0.03)$. The RDW values for those above 18 points and at or below 18 points were $14.95 \%$ 
and $14.18 \%$, respectively (Figure 7). Examining falls score by quintiles did not produce any significant differences between the quintiles.

There were no differences of average RDW values among quintiles of BMI or in comparison of subjects who were within and outside of a normal BMI range $(P=0.38)$.

Additionally, there were no significant differences in average RDW between subjects who had polypharmacy and those who did not $(P=0.98)$.

Eighty-one $(89.01 \%)$ of subjects experienced some degree of vision impairment. Of those with impairment, some subjects had additional vision-related diagnoses, which included cataracts $(27.17 \%)$, macular degeneration $(11.06 \%)$, glaucoma $(10.87 \%)$, retinopathy $(4.35 \%)$, and blindness $(2.17 \%)$. Subjects who were determined to have adequate vision did not have significantly different average RDW values in comparison with subjects in the categories of vision impairment $(P=0.44$, Figure 8$)$. There were also no differences in average RDW values seen between the categories for vision impairment.

Some subjects with mobility impairment had other mobility-related diagnoses, such as a diagnosis of gait impairment (43.48\%), debility (27.17\%), abnormal posture (11.96\%), and wandering behavior (3.26\%). No differences in average RDW values were seen among the categories of assistance levels for evaluation of mobility impairment (Figure 9).

\section{Examination of Logistic Regression Including Correlates of Falls}

Mono- and multivariate logistic regression was also performed (Tables 4 and 5). This included average RDW, vision impairment, mobility impairment, weight, BMI, polypharmacy, and facility falls risk scores. The odds ratios for the majority of variables included in both Tables 4 and 5 were less than 1 . However, no odds ratios were significant for any of the 
variables examined for falls in logistic regression analysis of either mono- or multivariate tests as the $95 \%$ confidence intervals for each variable included 1 .

\section{Longitudinal Analyses}

\section{Comparison of RDW in Subjects Who Did and Did Not Fall}

Longitudinal assessment of the change in RDW between subjects who fell compared to subjects who did not fall revealed that there was no significant difference between fallers and non-fallers for change in RDW $(P=0.62)$. Subjects who experienced 11 and 13 falls $ठ$ the highest in the studyð both had RDW changes of less than $0.5 \%$ over the study period, while subjects who experienced zero falls had RDW changes in excess of 5\% (Figure 10).

\section{Evaluation of RDW Values and Correlates of Falls}

There were no significant differences of change in RDW values between subjects who had changes of weight that were greater than $5 \mathrm{~kg}$ compared to those who did not $(P=0.59)$. The assessment of average RDW compared to change in weight yielded similar results to that addressing change in RDW (Figure 11). Additionally, there were no significant differences in average RDW between those who experienced a significant weight change of at least $10 \%$ over the final 6 months of the study compared those did not experience at least $10 \%$ weight change for that time $(P=0.15)$.

No significant differences were noted between subjects who experienced changes in BMI greater than $3 \mathrm{~kg} / \mathrm{m}^{2}$ compared to those who did not for either average RDW $(P=0.16)$ or change in RDW $(P=0.08$ ) (Figure 12). Differences were also not seen among quintiles of BMI change. 
There were no significant differences recorded for change in RDW in subjects experiencing polypharmacy compared to those who did not for the final quarter of recorded data. Data on polypharmacy experience for the beginning of data collection was not available and the result on change in polypharmacy was not able to be assessed.

In evaluation of the change in vision status categories, there were no significant differences noted for either change in RDW values or average RDW over the course of the study. The degree of change of RDW during the study was similar across categories of vision status changes (Figure 13). The results for changes in mobility status were similar to the results obtained for change in vision status for the assessment of both average RDW and change in RDW (Figure 14).

Additionally, there were also no significant differences among quintiles of facility falls scores either for change in RDW or average RDW. Values of change in RDW were similar among subjects who did and did not experience changes in facility falls scores (Figure 15).

\section{Discussion}

The main finding of this retrospective medical record review was that RDW levels were not significantly associated with falls. Additionally, the correlation between RDW values and the reported predictors of falls, which included weight, BMI, medication use, mobility impairment, vision impairment, and facility falls risk assessment scores was limited. There were two areas where significant results were obtained. The first of which was with the comparison of average RDW values in the highest weight quintile to values in the remaining lower weight quintiles $(P=0.02)$. The second area was in the evaluation average RDW values of subjects 
who were at or below the mean/median for fall risk scores compared to those who were above the mean/median fall risk score $(P=0.03)$.

\section{Cross-sectional Interpretation}

Results indicated that average RDW value was not significantly $(P=0.12)$ lower in subjects who experienced a fall $(14.31 \pm 1.69 \%)$ than in those who did not fall $(14.87 \pm 1.62 \%)$ (Figure 3, Table 2). A lower average RDW percentage in the group that experienced falls is in opposition of the hypothesis. Both fallers and non-fallers had an average RDW interquartile range that was within normal physiologic limits. This was also in opposition of the proposed hypothesis. While none of the individual comorbidities that were assessed demonstrated statistically different RDW values in comparison of those who did and did not fall, the non-faller subgroup contained higher percentages for the majority of the comorbidities examined (Table 2). Vayá et al. and Sánchez-Chaparro et al. found that an increased RDW was associated with metabolic syndrome. ${ }^{141,142}$ In the Vayá et al. study, subjects with metabolic syndrome $(n=61$, mean age $=51$ years $)$ were compared to similar subjects without metabolic syndrome $(n=94$, mean age $=50$ years $)$, revealing that $\mathrm{RDW}>14 \%$ was associated with metabolic syndrome $(\mathrm{OR}$ $3.55 ; 95 \% \mathrm{CI}, 1.15-9.70, P=0.026)$ and was similar to the association with abdominal obesity (OR 3.13; 95\% CI, 1.07-9.11, $P=0.036) .{ }^{142}$ The mechanism by which this is believed to occur is with the worsening of inflammation in those who are overweight. Inflammation does not allow for adequate maturation of red blood cells and may promote elevated RDW. ${ }^{141}$ However, Sánchez-Chaparro et al. found the association between RDW >14\% and metabolic syndrome (OR 1.14; 95\% CI, 1.07-1.21, $P<0.0001$ ) was not as strong as the association between RDW $>14 \%$ and cardiovascular disease (OR 1.24; 95\% CI, 1.04-1.50, $P=0.019$ ), which may suggest that accumulation of disease may be have a detrimental and disease-specific impact on RDW 
values. ${ }^{141}$ Chronic disease may promote depression or fatigue. This may be seen in subjects with cardiovascular-related conditions, arthritis, diabetes, and dementia who may be more likely to have depression and impaired mobility. ${ }^{138,139,140,143}$ These chronic diseases affected significant proportions of the study population (Table 2). The acuity of debility may have been great enough in this facility-dwelling sample that these subjects may not have been able to attempt to walk or move about the facility. This is supported by the higher numbers of subjects who did not fall who were also in the ñtotal dependenceòcategory of mobility status compared to subjects who experienced falls (Table 3). It is also plausible that there were subjects in this sample who experienced other health issues that were not related to either RDW or fall events. The subjects who experienced the highest number of falls in a yearôs time also had average RDW values that were among the lowest and within normal limits.

Subjects in the highest weight quintile had RDW values that were above normal limits, while subjects in the lower four quintiles had RDW values were within normal limits. However, when comparing subjects in the lowest weight quintile to the upper quintiles, there were no significant differences, and RDW values were within normal limits. According to the background information and the hypotheses, subjects who were at either of the weight extremes would have increased risk of falling and elevated RDW values compared to those not at risk. Additionally, weight that is in the extremes may be associated with increased illness and debility. ${ }^{58}$

The average RDW was also significantly different between subjects who had facility falls scores Òl 8 and $>18$ points $(P=0.03)$ (Figure 7). On the assessment, higher scores were received for items such as taking cardiovascular-related medications, magnitude of change in blood pressure upon standing, and diagnosis of cardiovascular-related conditions, which may help to 
explain the observed difference (Figure 5). No significant differences were seen at the 10-point threshold, which is indicated as the cutoff for increased risk to fall on the assessment.

Differences were only seen at the 18-point level. The mean RDW values for both these groups were below 15\%, even when the cutoff was set at 18 points. An insignificant positive trend between average RDW and increased facility falls score may reinforce that greater debility and decline could play a part in elevated RDW (Figure 6). However, examining quintiles of facility falls scores did not reveal any significant differences among their average RDW values.

No differences were detected in average RDW values between the categories in the graphs depicting vision and mobility statuses. It might have been expected that subjects in the most severe categories (ñ̃tal dependenceò and ñuighly impairedò vision) would have higher RDW values if greater inflammation and stress contribute to elevating RDW. The most severe categories may also have been thought to be reflective of accumulation and exacerbation of disease. $^{58}$

\section{Longitudinal Interpretation}

Examination of longitudinal results echoed the results of the cross-sectional findings with no association between change in RDW and total falls experienced by the subjects during the

data review period. Some disease processes have also been related to greater frailty. ${ }^{58}$ In a study assessing the ability of the Instrumental Activities of Daily Living (IADL) scale to predict the characteristics of frailty, subjects ( $n=7575$, Ó/5 years) who had at least one IADL disability were more likely to have heart disease, stroke, diabetes, and depression $(P=0.001) .{ }^{58}$ Additionally, after logistic regression, a fear of falling remained significantly associated with having at least one IADL impairment $(\mathrm{OR}=1.47 ; 95 \% \mathrm{CI}, 1.28-1.69) .{ }^{58}$ Similarly, in the current study, subjects who demonstrated elevated RDW and presence of chronic comorbidities 
and disease processes may also have been lacking in strength, coordination, and mental capacity to make an attempt to stand, walk, or transfer (and subsequently fall). The subjects who fell might have still been f̂nealthyò enough to attempt locomotion and transferring within the facility. The current study considered facility-dwelling residents, who may have additional chronic illnesses and diseases that may impact daily living activities to a greater degree than the community-dwelling subjects as reported in the study by Nourhashémi et al. ${ }^{58}$

The examination of change in RDW by change in weight produced a trend line that was in opposition of the predicted direction, indicating those who experienced a reduction in weight also experienced an increase in RDW while those gained weight had a decreased RDW over the study period. The MDS defines clinically significant weight changes as Ó5\% for a 30-day period or Ó10\% for a 180-day period. ${ }^{144}$ In a study of 900 nursing home residents, $48 \%$ experienced at least one monthly weight that significantly differed from the preceding weight over a 7-month evaluation. ${ }^{145}$ Those who had a clinically significant weight loss were at increased risk for death compared to those who gained weight by 10 -fold. ${ }^{145}$

It is also plausible that someone who is recovering from an illness or is healing from injury might be able to consume more calories, gain weight, and also attempt locomotion in postillness therapy. ${ }^{146}$ In a randomized controlled trial evaluating the effect of a physiotherapy and nutrition program against usual care post-illness in elderly subjects, nutritional status and function were strongly associated, and an inverse relationship was observed between activities of daily living (ADL) impairment and current dietary intakes. ${ }^{146}$ The trend line in examination of change in RDW by change in weight indicated that a gain in weight was insignificantly associated with a reduction in RDW. Change in RDW by change in BMI also revealed a similar trend between elevated RDW and elevated BMI. Those who had high changes in BMI had 
higher average RDW values than those who had lower changes in BMI. Some sources suggest assessing waist circumference for a more accurate assessment of excess weight in older adults. ${ }^{147}$ However, this information was not available for the current study.

Analysis of the impact of vision status on RDW revealed there was minimal difference in average RDW or change in RDW values based upon how much a subjectô vision changed over the course of the study. In Figure 13, there were few subjects in the categories beyond a onecategory improvement $(+1)$ or decline $(-1)$, so analyzing the degree of change may not be meaningful. The subjects who had a decline of three categories from the oldest data period to the most recent displayed an increase in RDW over the study period with a median increase of 3\%. However, their median for average RDW was approximately $15 \%$. This value is the upper limit of what is considered in the normal range for RDW.

Although RDW may be increased with chronic disease processes, it is possible that these patients also have decreased mobility and reduced daily activities. ${ }^{148,149}$ Therefore, it is difficult to predict how the relationship between RDW and mobility might be seen in those who are functionally and physiologically improving in the facility as the cohort in this current study did not include those in the therapy program at the facility.

The longitudinal assessment of facility falls score insignificantly trended with a change in RDW over time. As facility falls score increased, so did RDW (Figure 15). This was not the case in examining average RDW with the change in facility falls score. Falls risk score may decrease for reasons other than those directly related to RDW, such as becoming bed-bound, initiating palliative or hospice care measures, discontinuing medications, or adjusting to major onset of worsened disease, so a decrease in facility falls score may not necessarily be associated with a decrease in RDW only. ${ }^{71}$ 


\section{Limitations and Future Research}

A limitation of this study is that it is retrospective in nature. Documentation in some records was incomplete or information was missing. Not all residents may have had a complete set of tests done at similar time periods or intervals to make comparison meaningful. However, limiting the subjects included to only those with complete data would significantly decrease the sample size and exclude T̃nealthierò residents who may have less frequent laboratory measures and falls risk assessments. A resident who has more available laboratory reports to analyze may be more acutely ill than a resident with only routine laboratory analyses, contributing to a type of admission rate bias. ${ }^{150}$ The ability to identify racial/ethnic differences may be also limited. Sample characteristics were outlined in Table 2. Eighty-nine percent of the subjects were White and $80 \%$ were female, making comparisons among subgroups more difficult.

Furthermore, because the sample is a cohort comprised of older adults in a long-term care facility, which may include a higher proportion of subjects who are residing there for end-of-life care than would be seen in another older adult sample, this may have generated a sampling bias. Older adults who required skilled nursing care may have greater health needs, more chronic disease, and potentially different RDW values than would be found in the older adult population. It may be difficult to identify each possible condition that contributes to elevated RDW. ${ }^{151} \mathrm{Kim}$ et al. and Patel et al. have suggested that RDW is likely to represent an integrated summation of pathophysiologic processes. $^{31,152}$ Both RDW and falls have been associated with increased age, and chronic disease has been associated with fall events. ${ }^{15,31,58,151,153}$ In a long-term care facility, older adults may also be subject to sudden and extreme changes in condition, such as significant changes in weight, declines in physical and cognitive functioning, as well as the 
implementation of end-of-life practices. ${ }^{145,154,155}$ It may be worth examining the potential for associations in a slightly younger or community-dwelling sample. The ability to monitor periods of increased falls activity with other concurrent changes in subjectsôconditions, such as medication changes and functional or cognitive declines is also suggested.

Capturing change in some variables was difficult, particularly for vision status and mobility status, which were recorded as categorical variables. Subsequent studies may consider assigning a point system to these variablesôcategories. Additionally, this study did not record specific changes in medication regimens. This may be worth considering in future research, particularly if medications can impact RDW or are known to contribute to falls. Statin and aspirin use have been associated with higher RDW and mortality. ${ }^{156}$ The variable indicating medication use was also only recorded for the final time point. Having only one measure of medication use resulted in the inability to evaluate change in medication use over the study period. The variables for vision and mobility status were from nursing assessments and may have been subject to inconsistent or incorrect interpretation of functional status at the time of assessment. Potentially questionable results were obtained from the data on vision and mobility categories. For example, one subjectô vision was coded as r̃nighly impairedò in the oldest data, ñimpairedò in the middle two data points, and ñadequateò in the most recent data. That would indicate this subject had a great improvement over the course of a year. This could be possible if the subject experienced some type of ocular intervention from which healing was in progress. Another subject was coded as ñadequateò for the first and third time points, and ñimpairedò for the second and fourth time points. This type of coding is more likely reflective of inconsistencies among the nursing staff in assessment of the subject, or perhaps whether the 
subject happens to be wearing his or her corrective lenses at the time of assessment, yielding an inaccurate assessment.

For results regarding changes in weight, subsequent studies should determine whether these weight changes reflect a change that was from a weight that was too low to a healthy weight or from a healthy weight to a weight that is too high. This study also did not specifically aim to examine the relationship between RDW and vitamin D. Low vitamin D levels have been

associated with falls and future work should consider examining this relationship. ${ }^{110}$ Information on nutrient intake itself was limited in the present study. Other than that which is reflected in laboratory values, anthropometrics, and documented prescriptions of vitamin/mineral supplementation in the medication administration records, there was little information available to determine nutritional status.

\section{Conclusion}

Red cell distribution width has no association with fall events. A significant difference in RDW values was seen between subjects in the highest weight quintile compared to those in the lower four quintiles. RDW values for subjects in the highest weight quintile were greater than those in the lower four quintiles and above normal limits. However, RDW values for subjects in the lower weight extreme were not significantly different from the other RDW values. A significant difference in RDW values was also seen between subjects who were at or below the mean/median falls risk score and those who were above the mean/median. However, RDW values were within normal limits for those who were at or below the mean/median and those who were above the mean/median. Future research should aim to further define the capabilities of RDW to evaluate prognosis and risk, determine how changes in RDW reflect changes in 
outcome over time, and work to clarify the underlying physiologic mechanisms that lead to elevated RDW in inflammatory-related pathologies.

\section{Acknowledgement and Disclosure of Conflicts of Interest}

The author wishes to acknowledge David Crouch, Elizabeth Beeson, Fran Henderson, and the nursing staff of the long-term care site. Thank you for allowing this project to be conducted in the facility and for your support of the researcher for the duration of data collection.

Use of the statistical analysis software was made possible through a technology grant.

ñPartial support for this research came from a Eunice Kennedy Shriver National Institute of Child Health and Human Development research infrastructure grant, R24 HD042828, to the Center for Studies in Demography \& Ecology at the University of Washington.ò No direct funding or other resources were received to support this research. 


\section{Appendix}

\section{Tables and Figures}

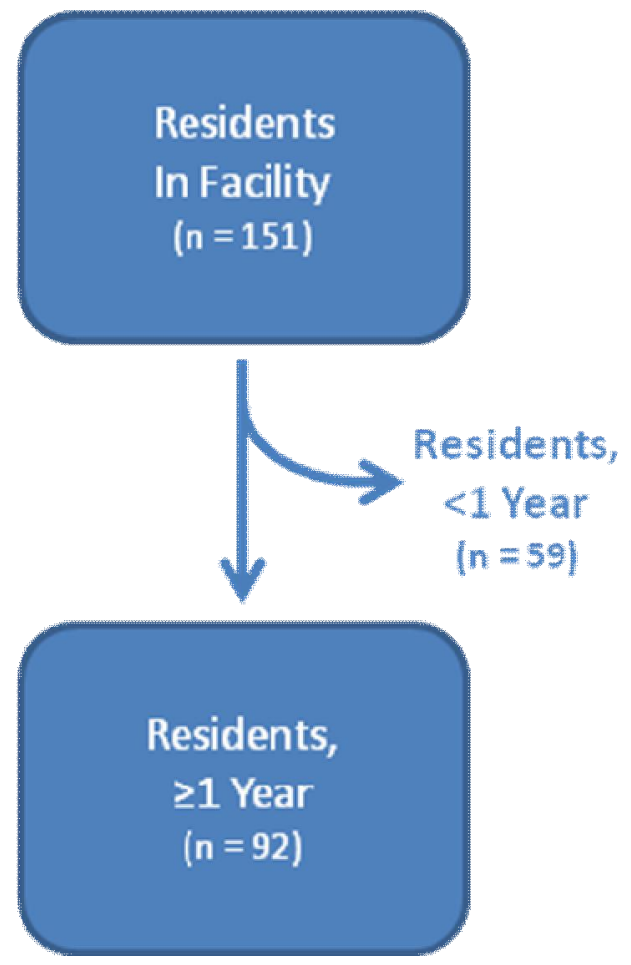

Figure 1. Flow diagram of subject inclusion/exclusion

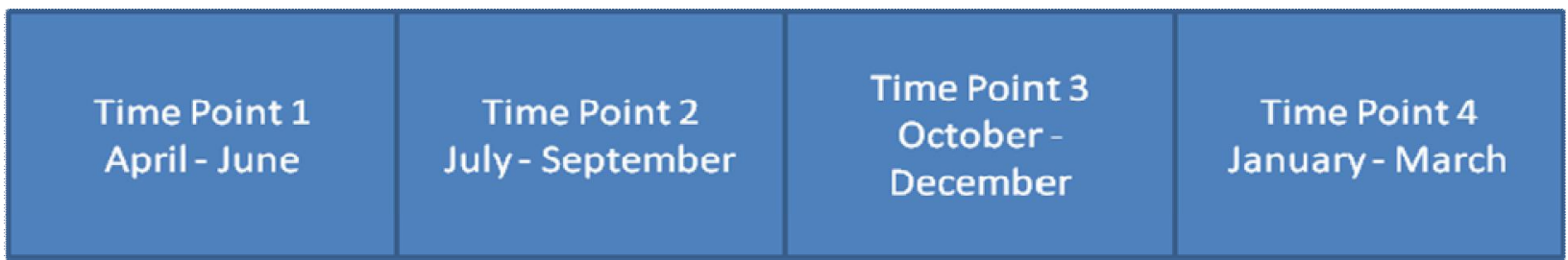

Figure 2. Data review periods for quarterly Time Points 


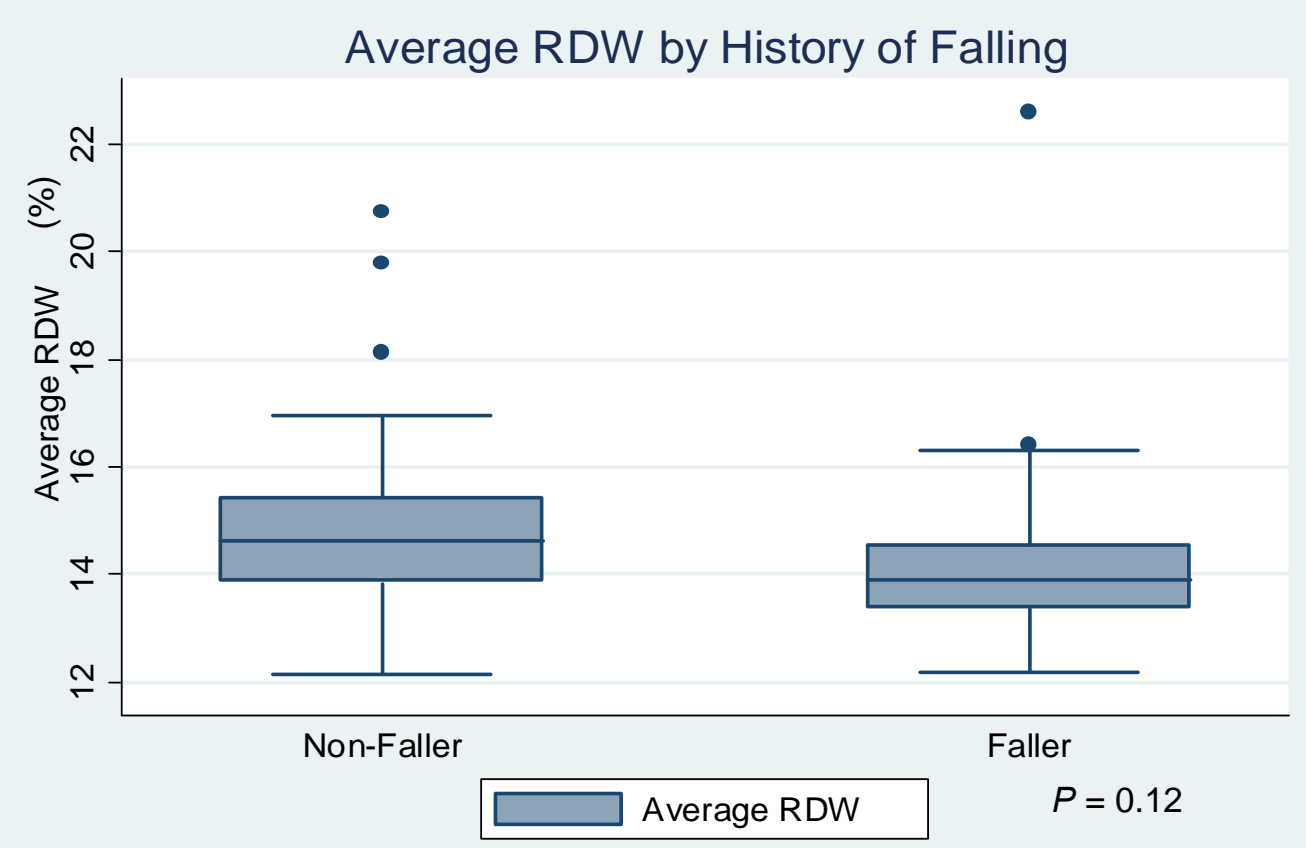

Average RDW among those who fell and did not fall during the study period.

Figure 3. Average RDW by history of falling during the study period. ( $P$ $=0.12)$.

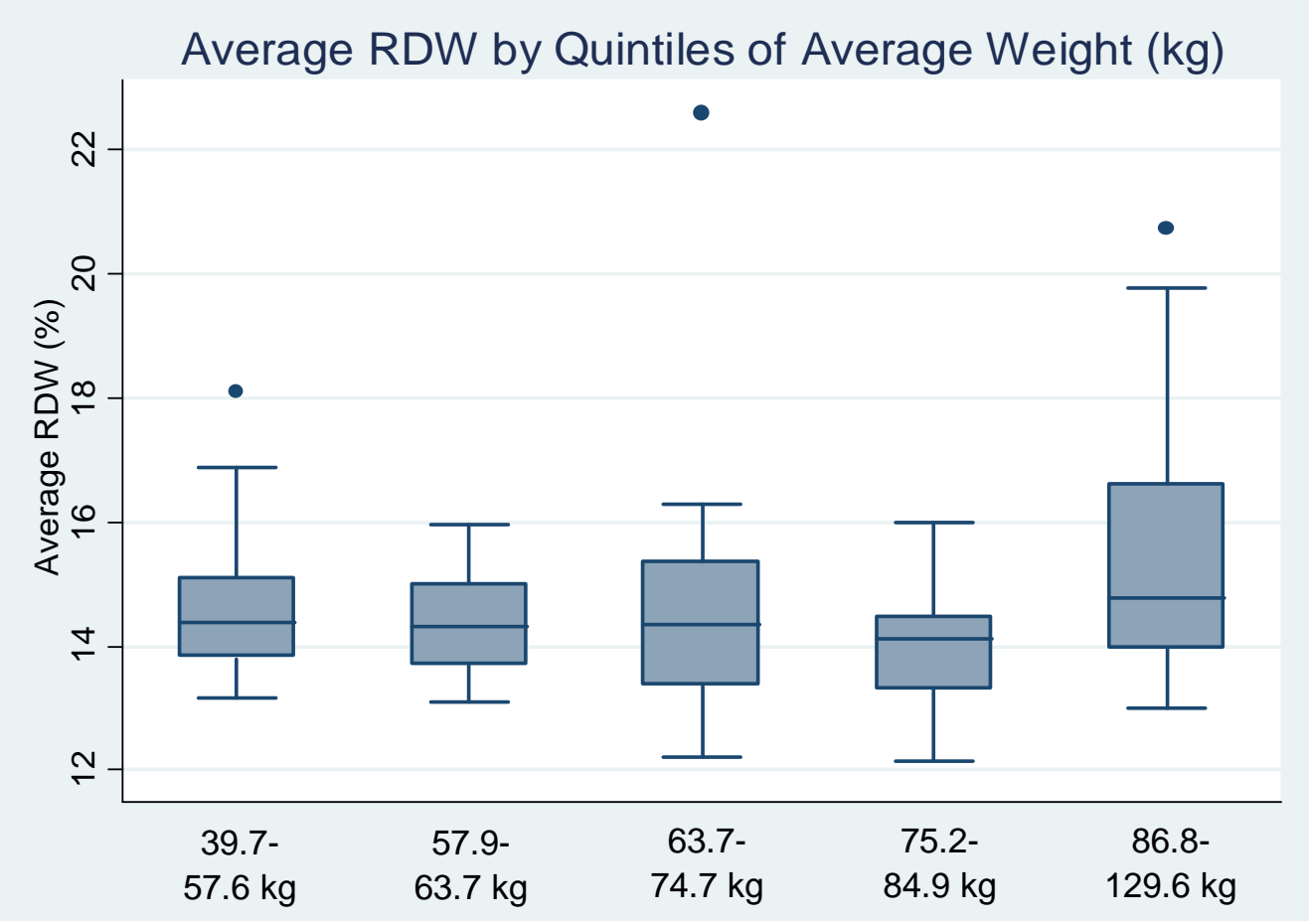

Figure 4. Quintiles of average weight. The average RDW values of subjects in the fifth quintile compared to those in the remaining quintiles resulted in $P$ $=0.02$, indicating this quintile had significantly different average RDW values from the other quintiles. 


\section{FALL RISK ASSESSMENT}

INSTRUCTIONS: Complete upon admission, quarteny, with any significant change in status, and at any other trme as indicated. Assess the resident and assign the most appropnate score for each item. A score of 10 or more indicates a "high risk" and a need to (1) address fall risk in the care plan, and (2) implement interventions to reduce or manage the identified risk factors.

NOTE Items in brackets ([ ] in first column indicate MDS items to which assessment area corresponds.

\begin{tabular}{|c|c|c|c|c|c|c|}
\hline \multicolumn{3}{|c|}{ ASSESSIMENT DATE } & & & & \\
\hline AREA OF ASSESSMENT & RESIDENT STATUS & SCORE & 1 & 2 & 3 & 4 \\
\hline MENTAL STATUS / & \multirow{3}{*}{ 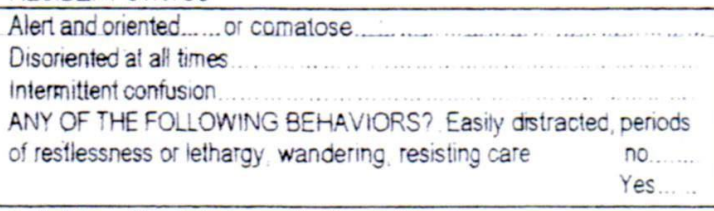 } & \multirow{3}{*}{$\begin{array}{l}0 \ldots \ldots \\
2 \ldots \ldots \ldots \\
4 \ldots \ldots \\
0 \\
2 \ldots \ldots \ldots \ldots\end{array}$} & & & & \\
\hline BEHAVIORS & & & & & & \\
\hline $\begin{array}{c}{[\mathrm{B} 2 \mathrm{a}, \mathrm{B} 4} \\
\mathrm{B} 5, \mathrm{E} 4 \mathrm{Aa}, \mathrm{e}]\end{array}$ & & & & & & \\
\hline $\begin{array}{l}\text { AMBULATION / } \\
\text { MOBILITY }\end{array}$ & \multirow{2}{*}{ 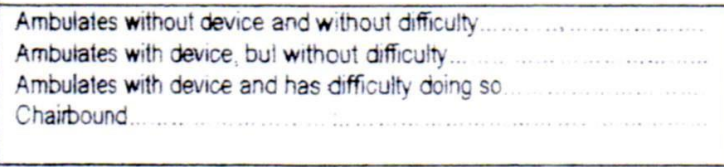 } & \multirow{2}{*}{$\begin{array}{l}0 \ldots \ldots \ldots \\
1 \\
4 \ldots \ldots \ldots \ldots \\
2\end{array}$} & & & & \\
\hline $\begin{array}{c}{[G 1 c, d, e, f} \\
G 5 a, d]\end{array}$ & & & & & & \\
\hline BALANCE & \multirow{2}{*}{$\begin{array}{l}\text { No balance difficullies, baiance normal...... } \\
\text { Balance difficulty while standing. } \\
\text { Balance difficulty while ambulating. } \\
\text { Balance difficulties with confusion or short-term merory problem } \\
\text { Requires physical assistance with all mobility tasks. }\end{array}$} & \multirow{2}{*}{$\begin{array}{l}0 \\
1 \\
1 \\
1 \\
2 \\
4\end{array}$} & & & & \\
\hline [G3] & & & & & & \\
\hline VISION STATUS & \multirow{2}{*}{$\begin{array}{l}\text { (ability to see in adequate light and with glasses, if used) } \\
\text { Adequate-can see reguiar print, detail in objects. } \\
\text { Slightly impaired---can see large print. } \\
\text { Moderately impaired--cannot see news headlines, sees objects } \\
\text { Highly or severely impaired---little vision or blind }\end{array}$} & \multirow{2}{*}{$\begin{array}{l}0 \\
0 \\
1 \\
2 \ldots \ldots \ldots \\
4 \ldots \ldots\end{array}$} & & & & \\
\hline$[D 1, D 2]$ & & & & & & \\
\hline ELIMINATION & \multirow{2}{*}{ 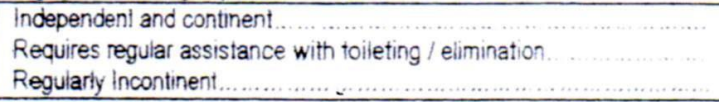 } & \multirow{2}{*}{$\begin{array}{l}0 \\
2 \\
4 \ldots \ldots\end{array}$} & & & & \\
\hline$[\mathrm{Gi}, \mathrm{H} 1]$ & & & & & & \\
\hline $\begin{array}{l}\text { SYSTOLIC BLOOD } \\
\text { PRESSURE }\end{array}$ & $\begin{array}{l}\text { No drop noted between lying and standing } \\
\text { Drop of less than } 20 \mathrm{~mm} \mathrm{Hg} \text { between lying and standing } \\
\text { Drop of } 20 \text { or more } \mathrm{mm} H \mathrm{HG} \text { between lying and standing }\end{array}$ & $\begin{array}{l}0 \\
2 \ldots \\
4 \ldots\end{array}$ & & & & \\
\hline MEDICATIOINS & \multirow[b]{2}{*}{ 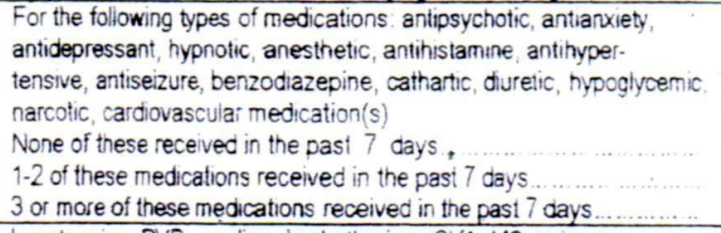 } & & & & & \\
\hline$[04 a e]$ & & & & & & \\
\hline $\begin{array}{c}\text { DISEASES and HEALTH } \\
\text { CONDITIONS }\end{array}$ & \multirow{2}{*}{$\begin{array}{l}\text { hypotension, PVD, cardiac dysthythmias, CVA, MS, seizures, } \\
\text { Parkinson's, Disease, arthritis, osteoporosis, fractures. missing } \\
\text { limb(s), loss of sensation or movement or both of limb(s). vertigo, } \\
\text { dementia or Alzheimer's Disease, s/s delirium, dehydration, } \\
\text { mainutrition, joint pain, } \\
\text { None of these present. } \\
1-2 \text { of these present... } \\
3 \text { or more of these present. }\end{array}$} & \multirow[b]{2}{*}{$\begin{array}{l}0 . \\
2 . \\
4\end{array}$} & & & & \\
\hline $\begin{array}{l}{[B 5, G 4 b, G 4 d, 11 e, \mid 11} \\
111-0,11 q, 11 t, 11 u-v, 11 w \\
11 y, 11 a a, J 1 f, J 3 g]\end{array}$ & & & & & & \\
\hline HISTORY OF FALLS & \multirow{2}{*}{$\begin{array}{l}\text { No falls in the past } 3 \text { months } \\
1-2 \text { falls in the past } 3 \text { months } \\
3 \text { or more falls in the past } 3 \text { months }\end{array}$} & \multirow{2}{*}{$\begin{array}{l}0 . \\
2 . \\
4 .\end{array}$} & & & & \\
\hline$[\mathrm{J4}]$ & & & & & & \\
\hline TOTAL SCORE & $\begin{array}{l}\text { A SCORE OF } 10 \text { OR HIGHER INDICATES RESIDENT IS AT HIGH } \\
\text { RISK FOR FALLS. }\end{array}$ & $>$ & & & & \\
\hline
\end{tabular}

\begin{tabular}{|l|l|l|l|}
\hline Assessment Date & Signature and Title & Assessment Date & Signature and Title \\
\hline (1) & & $(3)$ & \\
\hline$(2)$ & & $(4)$ & \\
& & & \\
\hline
\end{tabular}

\begin{tabular}{|l|l|l|l|}
\hline RESIDENT NAME & ROOM NUMBER & MED REC NO & PHYSICIAN \\
\hline & & & \\
\hline
\end{tabular}

Figure 5. In-house facility falls risk assessment tool indicating a score of $\geq 10$ should be considered as increased risk for falling. 


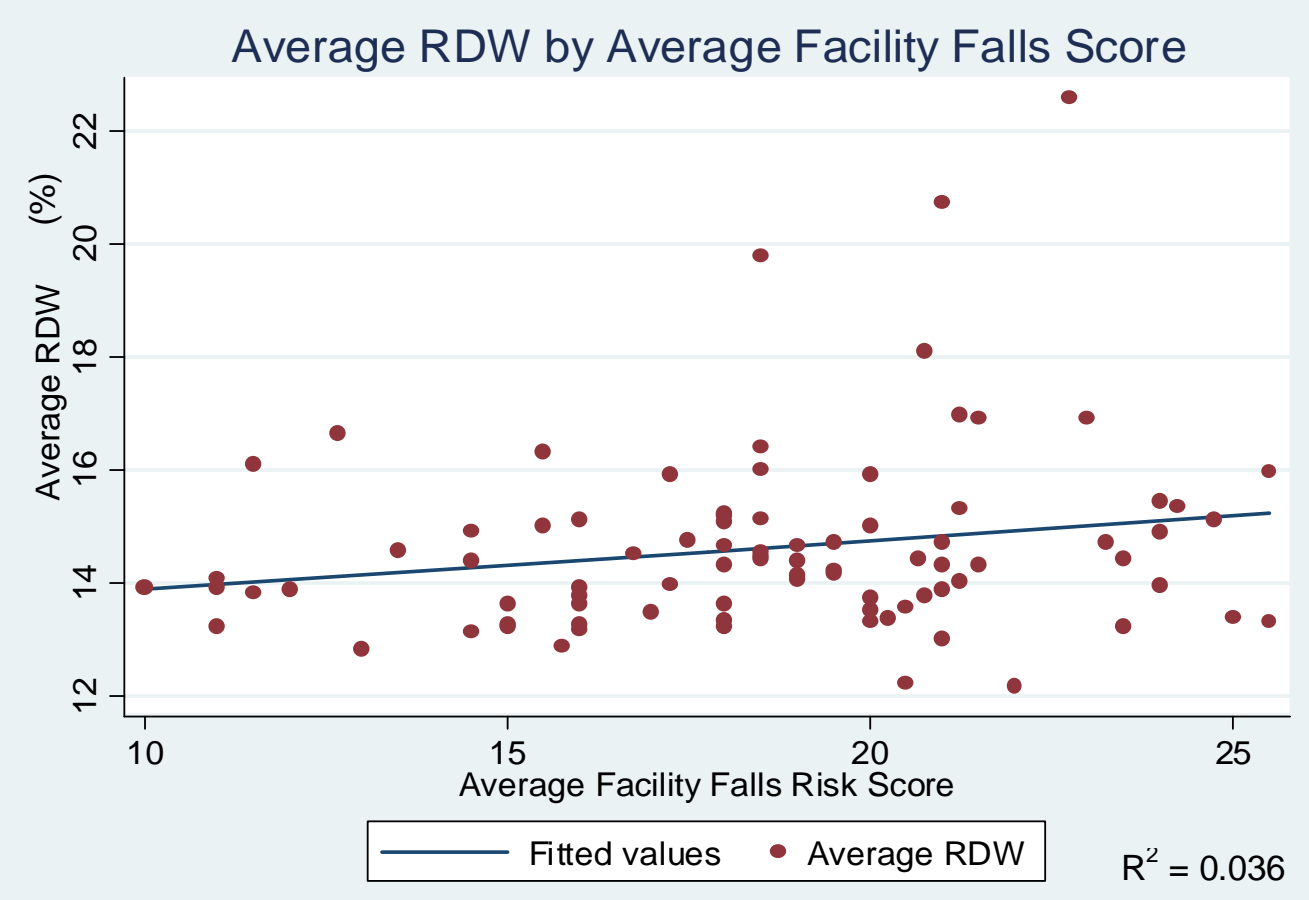

Figure 6. Average RDW by average in-house facility falls assessment score.

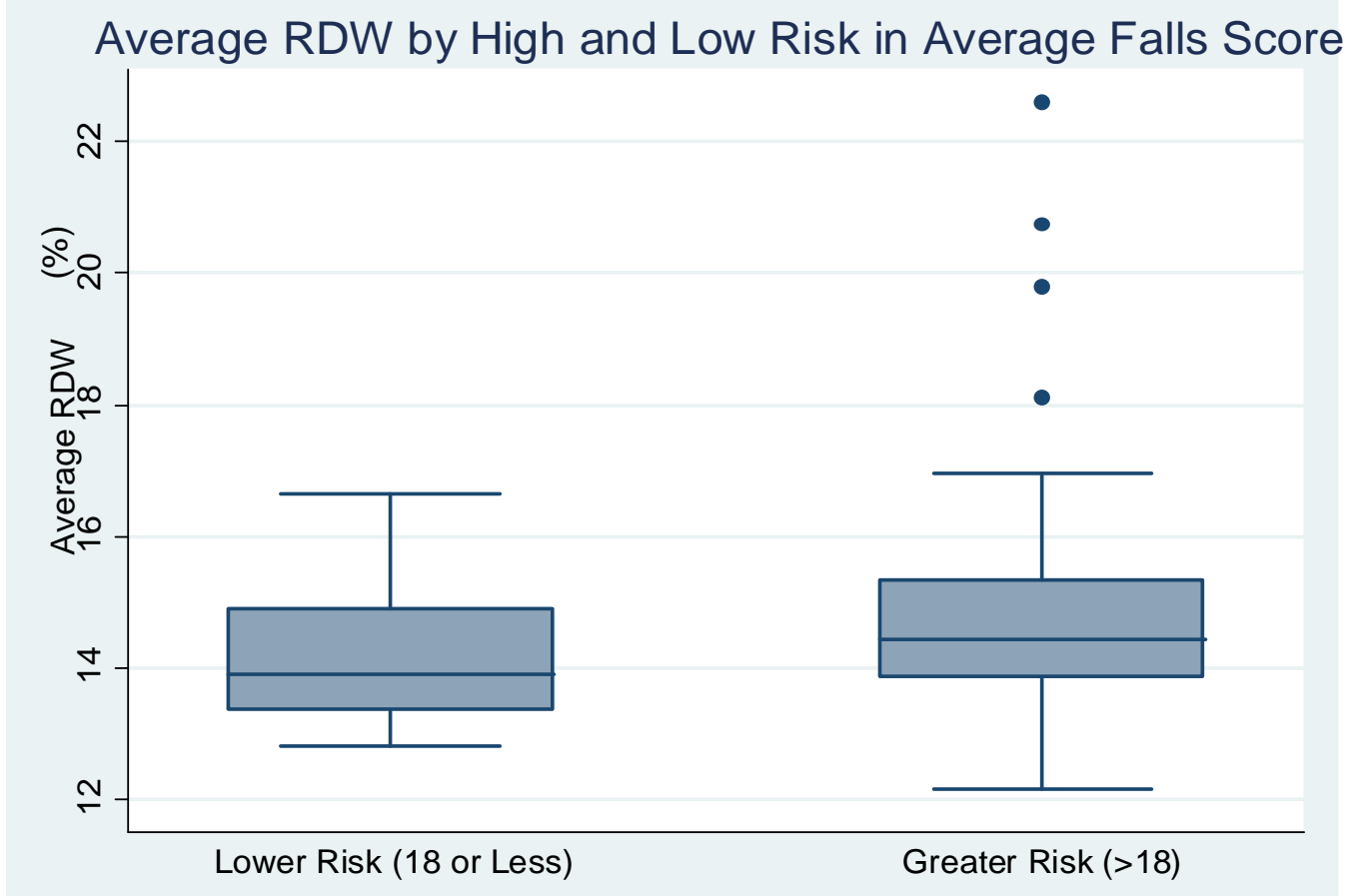

Figure 7. Average RDW by facility falls score considering risk as determined by an average score of 18 or fewer points versus greater than 18 points. A significant difference in average RDW values between lower and greater risk subjects was seen, $P=0.03$. 


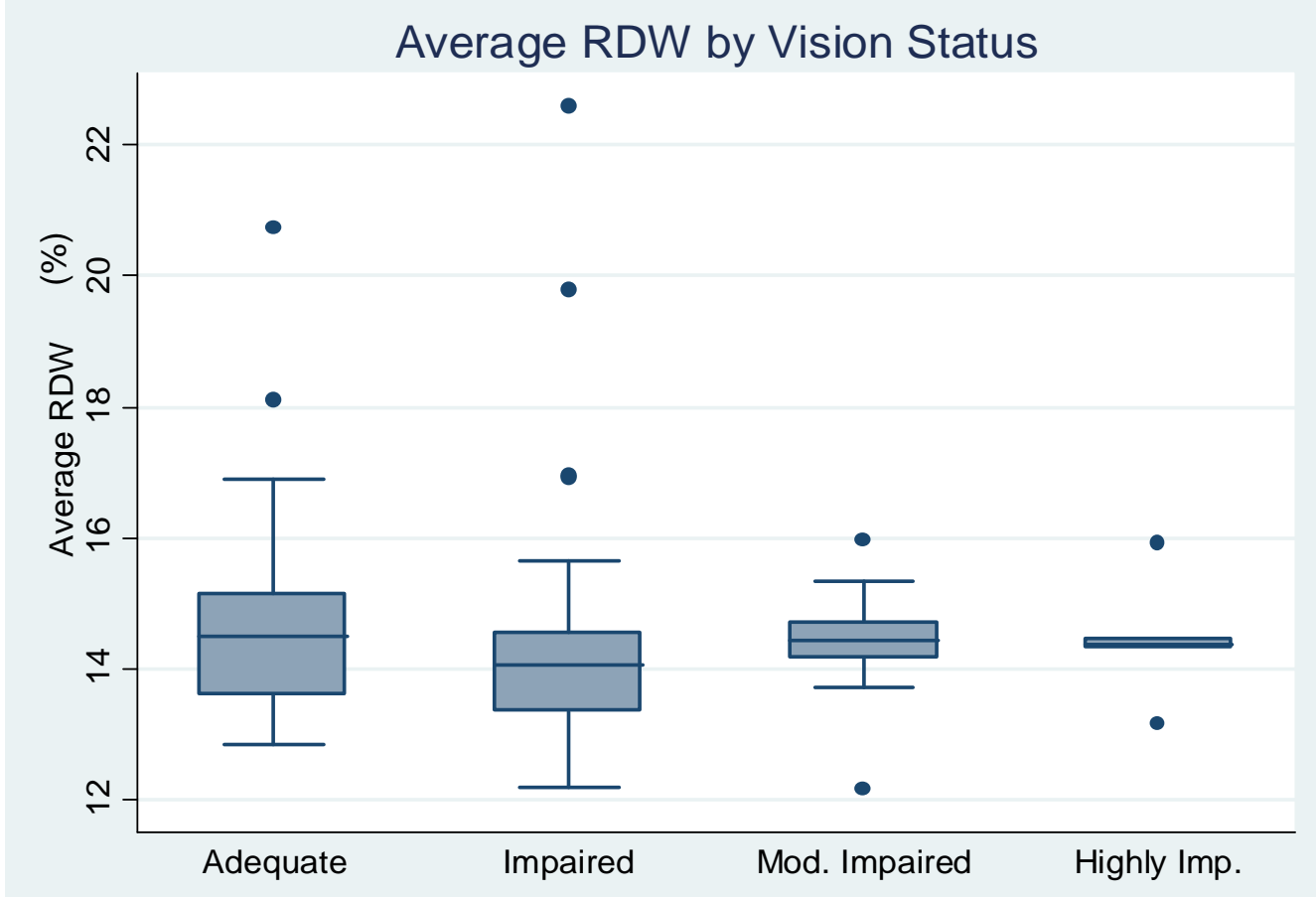

Figure 8. Average RDW by vision status used from Time Point 4. The average RDW values in those with adequate vision compared to those with any vision impairment were not different, $P=0.44$.

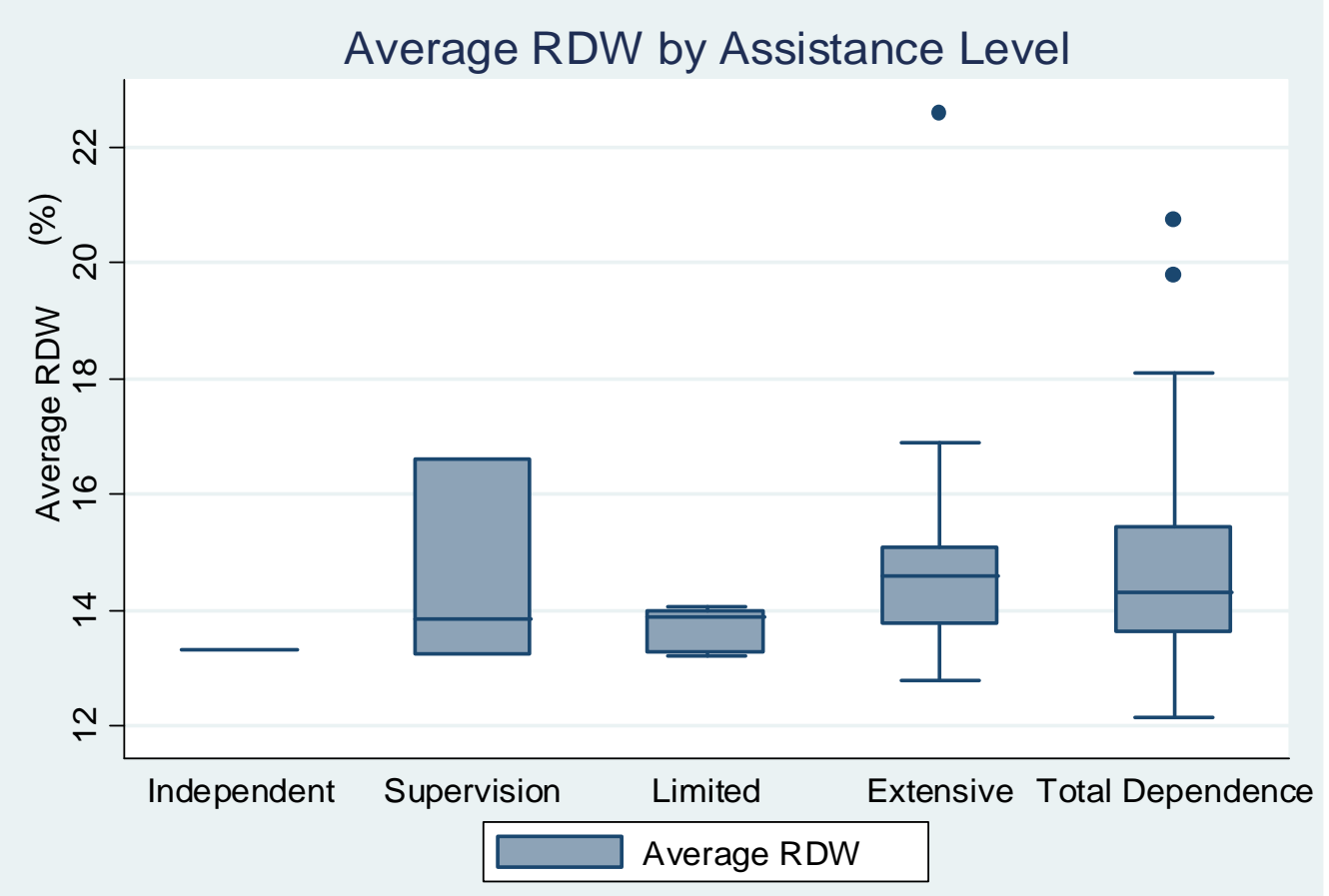

Figure 9. Average RDW by assistance level categories for mobility used from Time Point 4. 


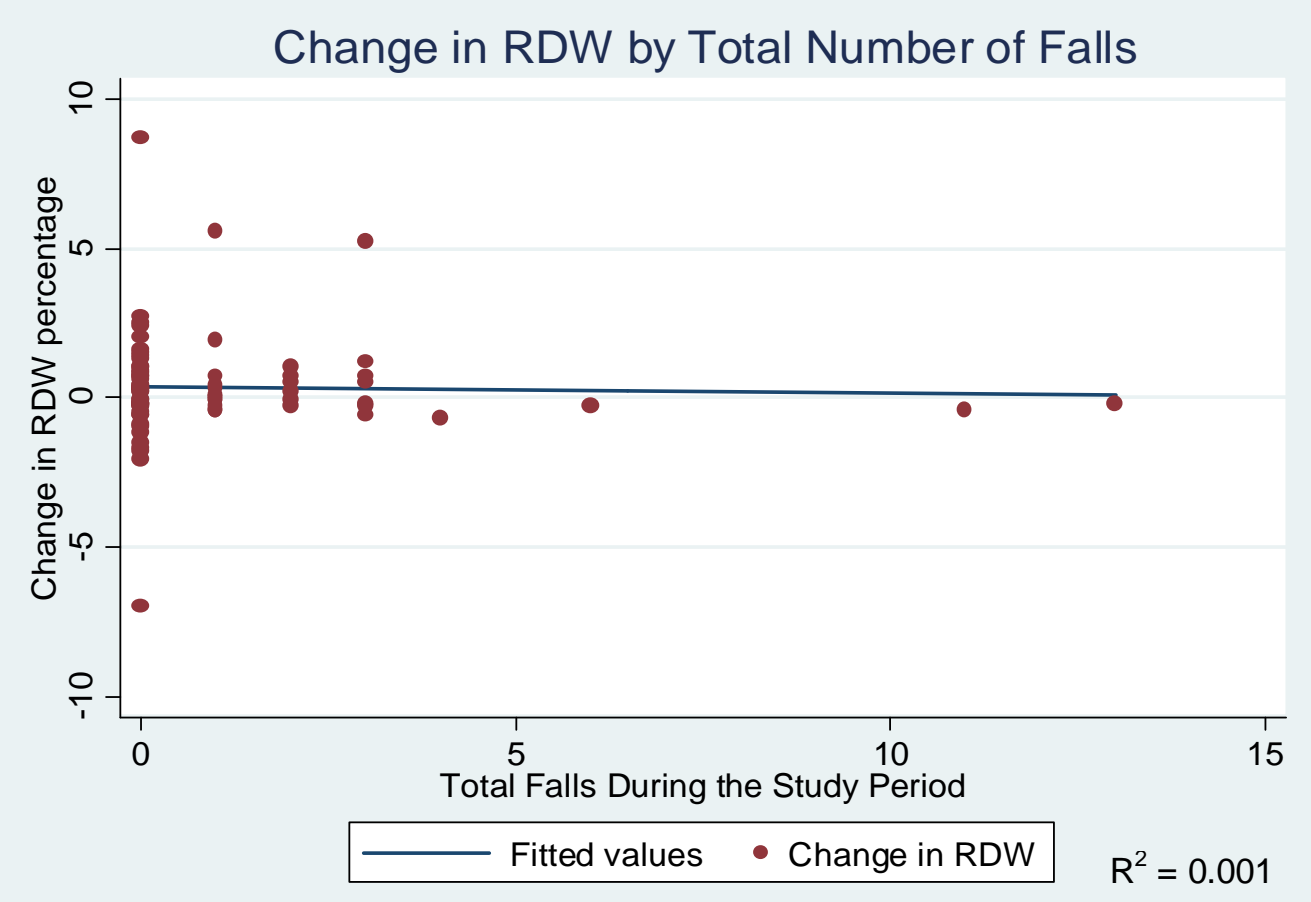

Figure 10. Change in RDW by the total number of falls a subject experienced during the study period.

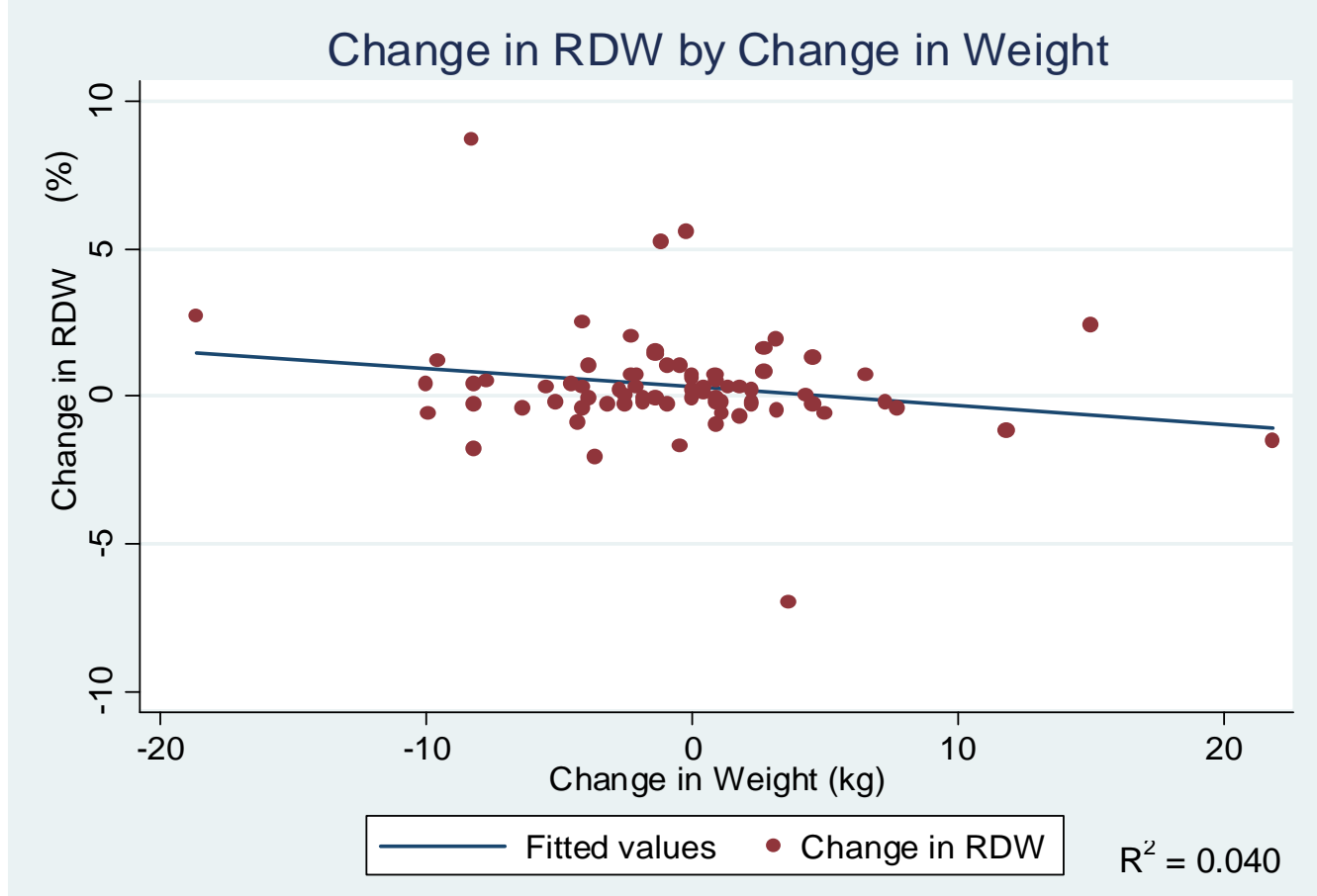

Figure 11. Change in RDW by change in weight. 


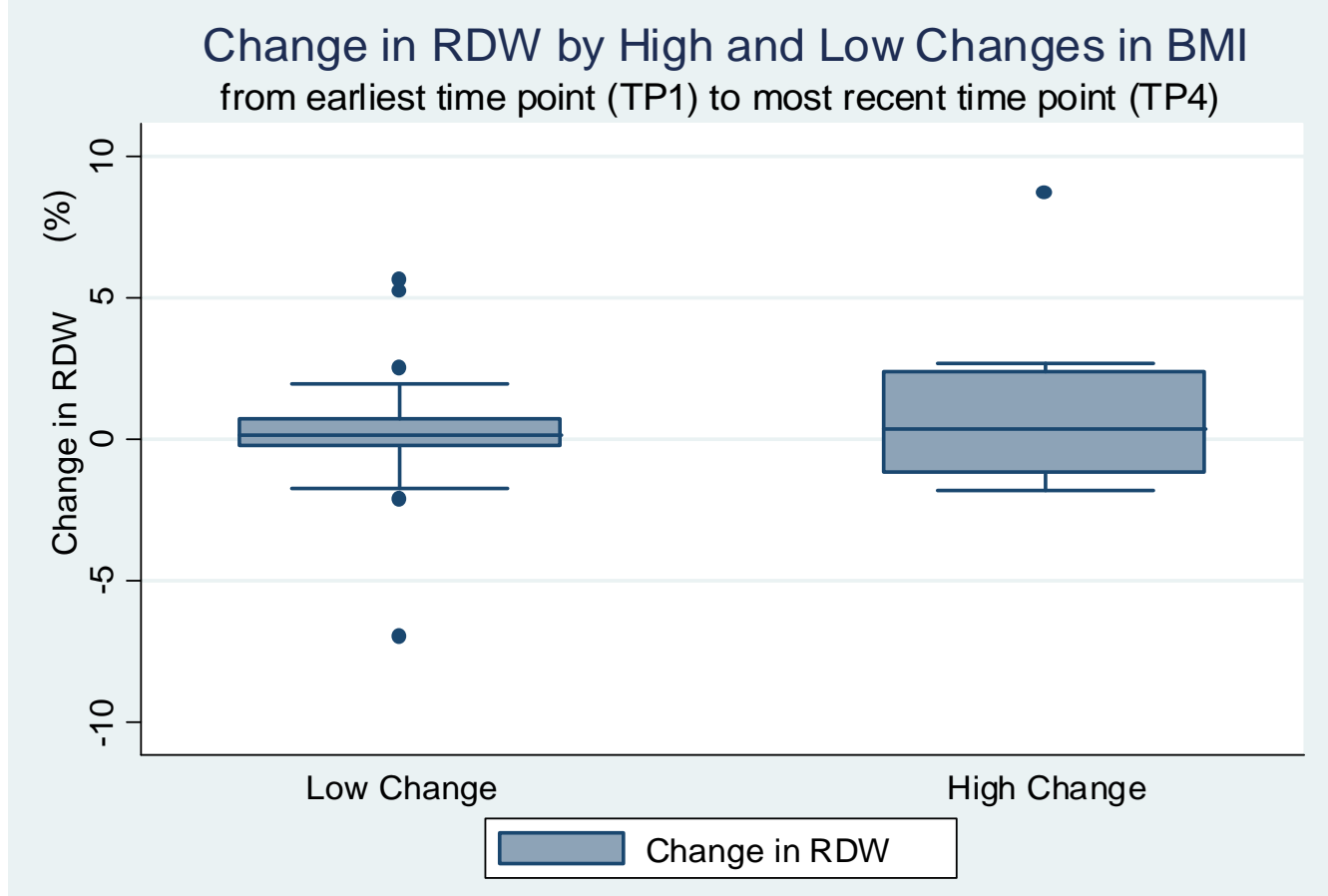

Figure 12. Change in RDW by changes in BMI that were O̊̉ $\mathrm{kg} / \mathrm{m}^{2}$ (low change) and $>3 \mathrm{~kg} / \mathrm{m}^{2}$ (high change), $P=0.08$.

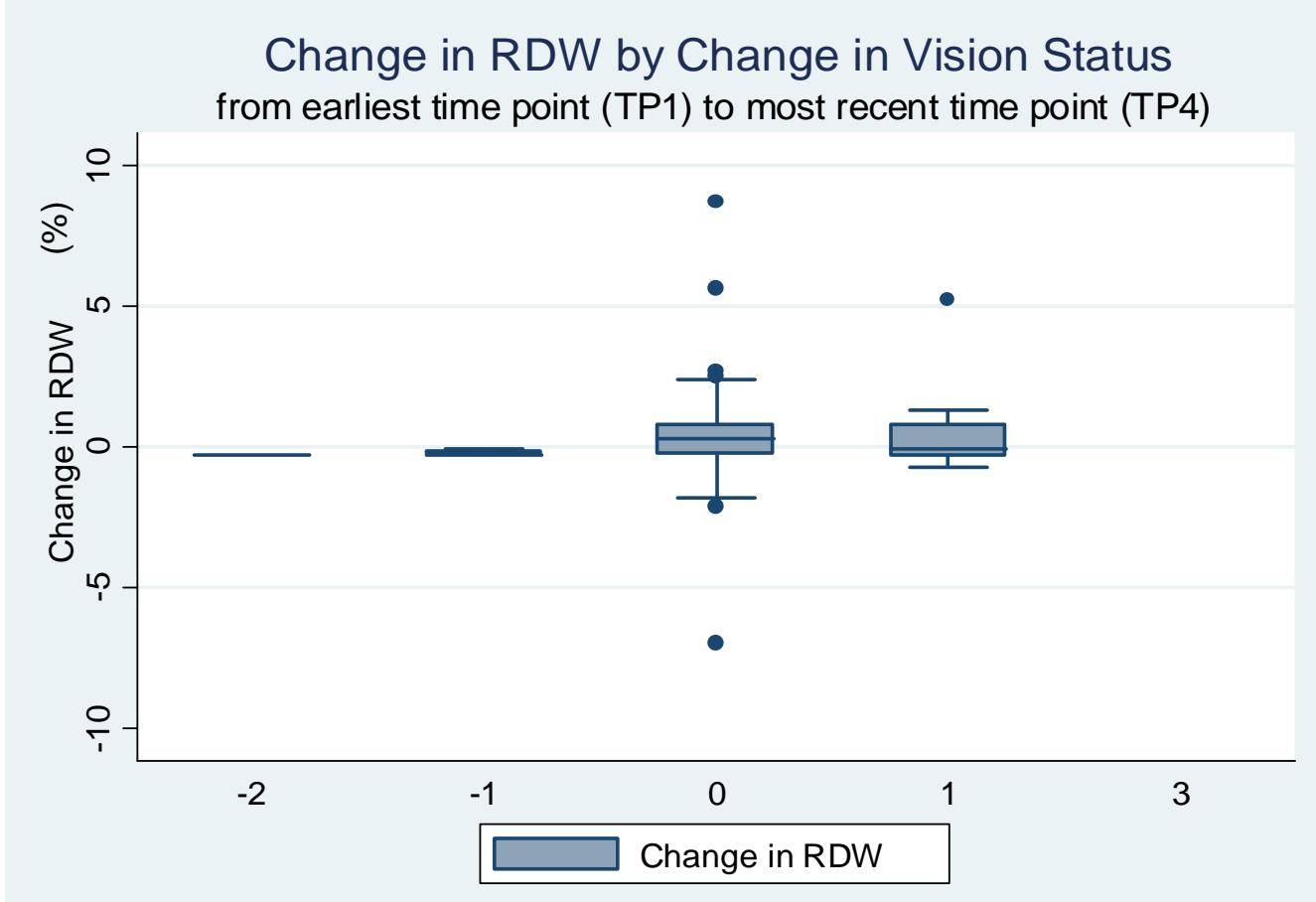

Figure 13. Change in RDW by change in vision status. Positive numbers indicate an improvement over the course of the study period, while negative numbers indicate a decline in functional ability. 


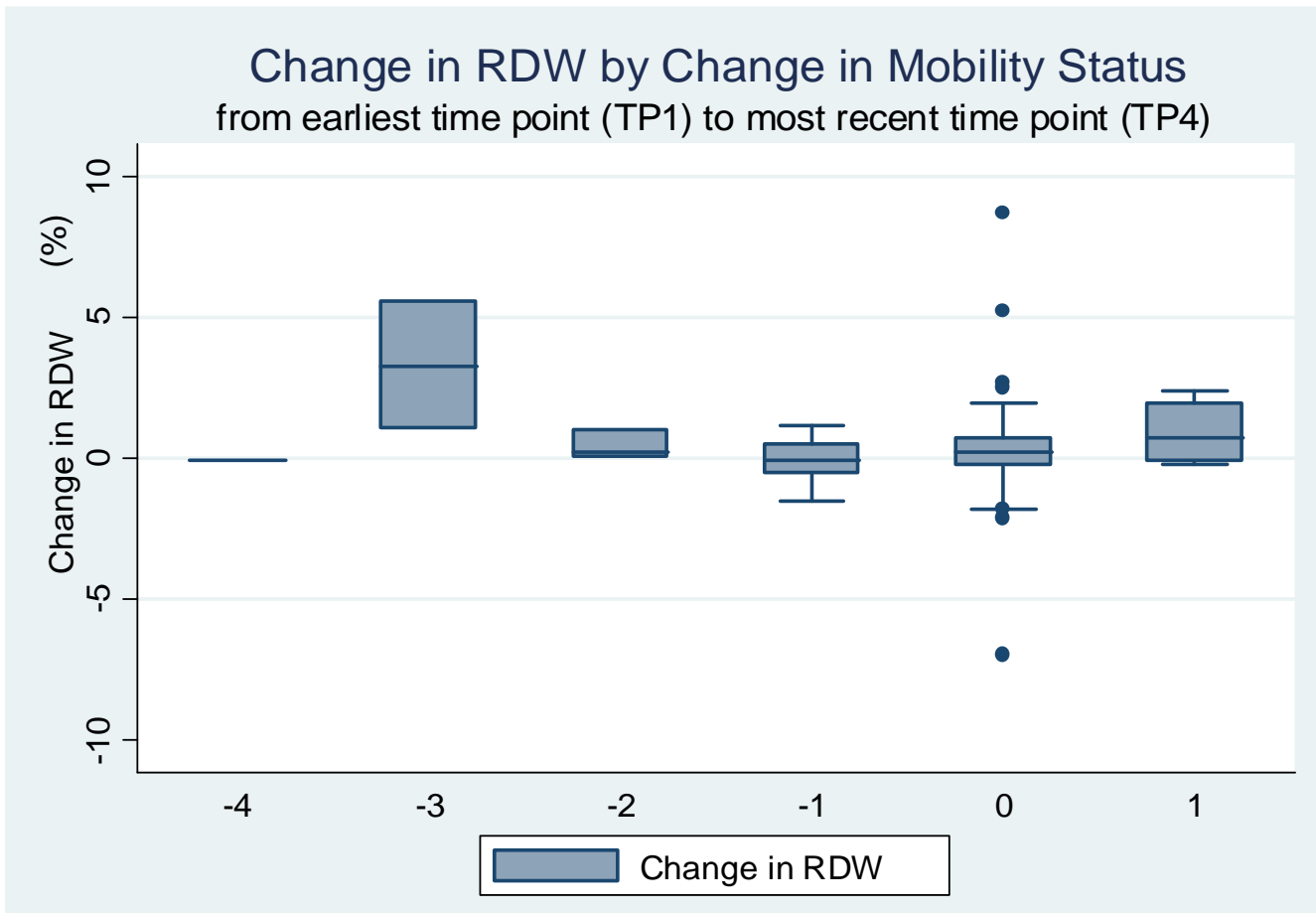

Figure 14. Change in RDW by change in mobility status. Positive numbers indicate an improvement over the course of the study period, while negative numbers indicate a decline in functional ability.

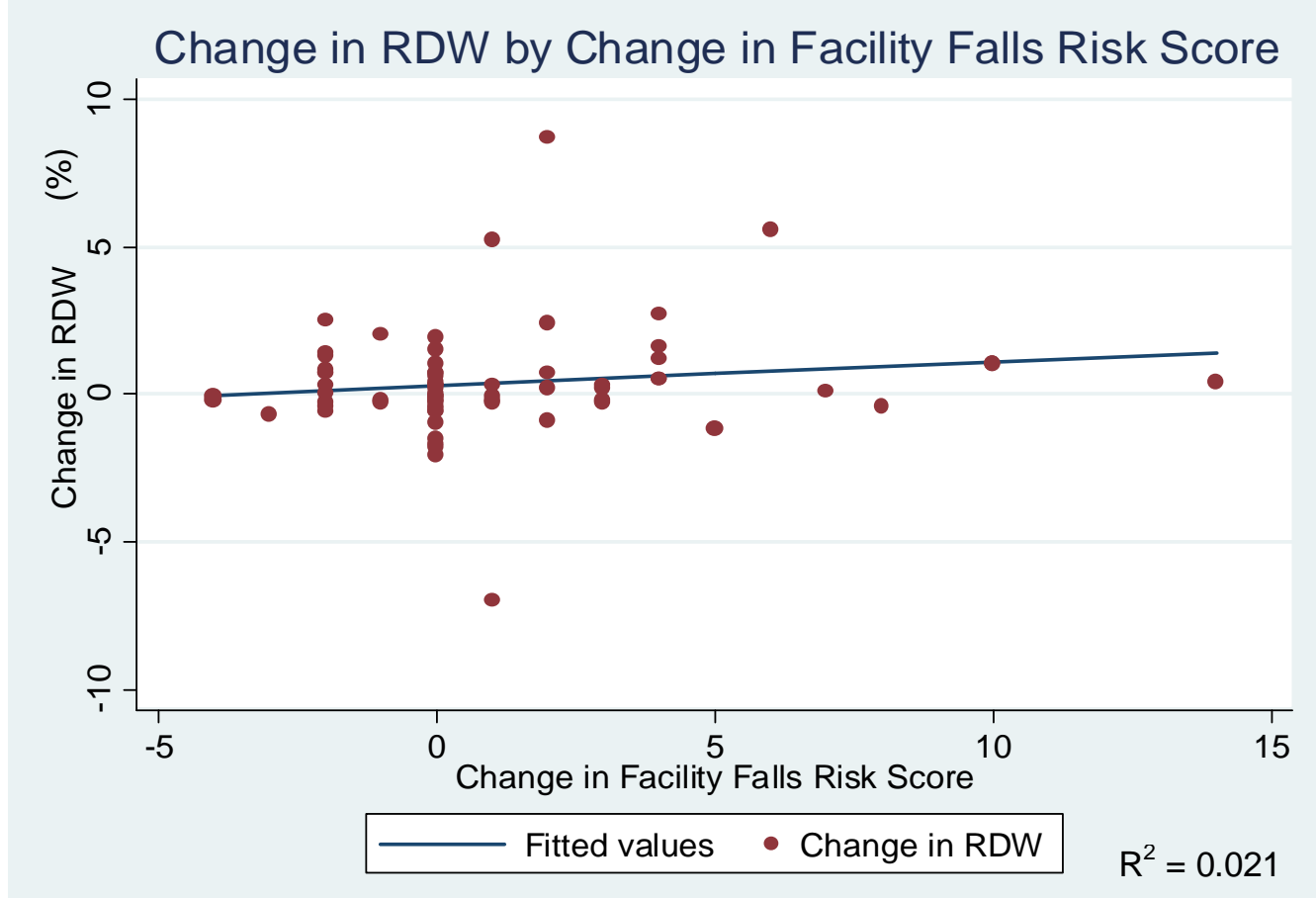

Figure 15. Change in RDW by change in facility falls score over the study period. 


\section{Table 1. Fall Assessment Tools}

Timed Up and Go Test

- Adapted from original Get Up and Go Test, component of time added to decrease subjectivity

- Participants rise from a chair, walk 3 meters, turn around, walk back, and sit in chair

- Scored 1 (normal) to 5 (severely abnormal)

- Analyzing time to complete individual tasks within the series of events may reveal functional deficits more clearly

- Equipment: chair, stopwatch ${ }^{157}$

- $87 \%$ sensitivity ${ }^{158}$

Berg Balance Scale

- 14 subtests graded with possible scores of 0 to 4 points

- Scoring may vary from grader to grader

- Stand to sit, stand unsupported, sit unsupported, sit to stand, transferring, stand with eyes closed, stand with feet together and outstretched arms, pick up object from floor, turn to look behind, turn in a full circle, place alternate foot on stool, stand with one foot in front of the other, and stand on one foot are the assessed tasks

- Equipment: chair, foot stool, tape measure, stopwatch ${ }^{159}$

- $53 \%$ sensitivity, and inconsistent data in selection of an ñat-riskòcut off score ${ }^{159,160}$

Falls Efficacy Scale

- Patients self-report on 10 items with scoring 1 (very confident) to 10 (not confident at all)

- 10 activities of daily living include: bathing, reaching into cabinets/closets, walking in house, preparing meals, moving in/out of bed, answering door/telephone, getting in/out of chair, dressing, personal grooming, getting on/off toilet

- Equipment: scoring sheet, pen/pencil

- Necessitates that patients have adequate cognition to record their answers on paper or verbalize their responses in a realistic and appropriate manner ${ }^{161}$

\section{4-Stage Balance Test}

- Patient engages in four different foot position configurations for at least 10 seconds each

- If the patient is unable to maintain these positions, he is at risk to fall

- Equipment: stopwatch

- Instructions indicate that the test administrator should be ready to catch the patient should he lose his balance ${ }^{162}$

\section{0-Second Chair Stand Test}

- Tests leg strength and endurance

- Equipment: chair, stopwatch 
- Patient sits in a chair and crosses arms across chest to form an ñXò with fingertips towards or on the shoulders, the patient then moves to a standing position and back to a seated position

- Patients are determined to be at risk if a certain number of ñstandsò are not completed in 30 seconds, taking into consideration the patient $\hat{Q}$ age and gender ${ }^{162}$

- Test-retest reliability between $0.84-0.92$, and construct validity indicated for patients in their 60s, 70s, and 80s ${ }^{163}$

Tinetti Assessment Tool

- Patient performs sitting balance, arises from sitting position, standing balance, balances with a ñnudge,ò stands with eyes closed, turns in a circle, returns to seated position, analysis of gait includes initiation, step height/length, symmetry, continuity, path, trunk sway, and stance

- Scores options are three point ordinal with 0,1 , or 2 for activities

- Time to administer the test is 10-15 minutes

- Sensitivity $76 \%$, specificity $66 \%$, interrater reliability agreement reported at $85 \%{ }^{164-167}$

\section{The Romberg Test}

- Investigates ataxia and sense of positioning

- Subject stands upright with hands at sides and eyes closed for a full minute

- If the subject sways or falls during the test, balance is impaired

- Equipment: stopwatch

- Test administrator is advised to be ready to catch the subject if he beings to fall ${ }^{167,168}$

The Trendelenburg Test

- Assesses hip abductor muscle function and progressive muscle atrophy

- Test administrator stands behind subject and observes subjectôs balance on one foot, the foot that is raised off the floor is bent at a 30-degree angle below the level of the opposite knee, the subject then is asked to raise the non-stance side of the pelvis as high as possible

- A normal result is holding of this pose for 30 seconds with the vertebra prominens centered over the hip joint and balanced foot

- Equipment: stopwatch

- The test requires the administrator to be able to observe the alignment of the pelvis, necessitating the subject to wear tight-fitting or minimal clothing

- False-positives, false-negatives, and delayed positives are common with this test ${ }^{169}$

\section{The Functional Reach Test}

- The subject stands with one shoulder near a wall where a yardstick is mounted horizontally, the subject raises his arms to shoulder height and the position of the knuckle on the middle finger is recorded on the yardstick, then the subject leans over as far as he 
can and the distance of reach as given by the middle knuckle is recorded

- Method comparison study indicates there are compensatory tactics that subjects engage in to avoid losing balance during the test, such as trunk movement, and that the test is not a strong measure of stability in elderly subjects ${ }^{170}$

- Equipment: yardstick mounted to wall, pen to mark on wall

Falls Risk Assessment Tool (FRAT)

- Assesses history of falls, classes of medications used, specific psychological diagnoses, and cognitive status

- Risk factors such as vision, mobility, transfers, behaviors, activities of daily living (ADLs), the environment, nutrition, and incontinence are also evaluated

- Specificity 0.92 , positive predictive value 0.57 , sensitivity 0.42

- Evaluation of FRAT suggests a wide variety of healthcare-related disciplines find it practical to use on a regular basis ${ }^{171}$ 
Table 2. Sample Characteristics

\begin{tabular}{|c|c|c|c|}
\hline Variables & $\begin{array}{c}\text { Total / } \\
\text { Mean Value } \\
\mathrm{n}=92 \\
\end{array}$ & $\begin{array}{c}\text { Subjects Who } \\
\text { Experienced a Fall } \\
\mathrm{n}=38\end{array}$ & $\begin{array}{c}\text { Subjects Who } \\
\text { Did Not Fall } \\
n=54\end{array}$ \\
\hline Age (years) & $88.19 \pm 8.03$ & $86.66 \pm 9.68$ & $89.28 \pm 6.51$ \\
\hline Sex & - & - & - \\
\hline Female & $74(80.43 \%)$ & $31(81.58 \%)$ & $43(79.63 \%)$ \\
\hline Male & $18(19.57 \%)$ & $7(18.42 \%)$ & $11(20.37 \%)$ \\
\hline Race & - & - & - \\
\hline White & $81(89.01 \%)$ & $31(83.78 \%)$ & $50(92.59 \%)$ \\
\hline Black & $4(4.40 \%)$ & $1(2.70 \%)$ & $3(5.56 \%)$ \\
\hline Asian & $3(3.30 \%)$ & $2(5.41 \%)$ & $1(1.85 \%)$ \\
\hline Hispanic & $2(2.20 \%)$ & $2(5.41 \%)$ & $0(0.0 \%)$ \\
\hline N. Am. Indian & $1(1.10 \%)$ & $1(2.70 \%)$ & $0(0.0 \%)$ \\
\hline Education & - & - & - \\
\hline$\leq 12$ years & $42(47.19 \%)$ & $16(43.24 \%)$ & $26(50.00 \%)$ \\
\hline$>12$ years & $47(52.81 \%)$ & $21(56.76 \%)$ & $26(50.00 \%)$ \\
\hline Smoking Status & - & - & - \\
\hline Never & $77(85.56 \%)$ & $34(89.47 \%)$ & $43(82.69 \%)$ \\
\hline Former & $13(14.44 \%)$ & $4(10.53 \%)$ & $9(17.31 \%)$ \\
\hline Payment Status ${ }^{\grave{A}}$ & - & - & - \\
\hline Private Pay & $22(23.91 \%)$ & $8(21.05 \%)$ & $14(25.93 \%)$ \\
\hline Paid For/Other & $70(76.09 \%)$ & $30(78.95 \%)$ & $40(74.07 \%)$ \\
\hline Co-morbidities & - & - & - \\
\hline Arthritis & $54(58.70 \%)$ & $22(57.89 \%)$ & $32(59.26 \%)$ \\
\hline Cardiovascular Disease $\mathrm{y}^{\ddot{y}}$ & $61(61.62 \%)$ & $21(55.26 \%)$ & $40(74.07 \%)$ \\
\hline Congestive Heart Failure & $24(26.09 \%)$ & $5(13.16 \%)$ & $19(35.19 \%)$ \\
\hline Dementia & $67(72.83 \%)$ & $28(73.68 \%)$ & $39(72.22 \%)$ \\
\hline Depression & $66(71.74 \%)$ & $28(73.68 \%)$ & $38(70.37 \%)$ \\
\hline Diabetes Mellitus & $28(30.43 \%)$ & $10(26.32 \%)$ & $18(33.33 \%)$ \\
\hline Digestive Impairment & $68(73.91 \%)$ & $25(65.79 \%)$ & $43(79.63 \%)$ \\
\hline Hypertension & $64(69.57 \%)$ & $29(76.32 \%)$ & $35(64.81 \%)$ \\
\hline Malnutrition & $6(6.52 \%)$ & $2(5.26 \%)$ & $4(7.41 \%)$ \\
\hline Obesity/Overweight & $5(5.43 \%)$ & $2(5.26 \%)$ & $3(5.56 \%)$ \\
\hline Pulmonary Disease & $22(23.91 \%)$ & $5(13.16 \%)$ & $17(31.48 \%)$ \\
\hline Renal Disease & $39(42.39 \%)$ & $17(44.74 \%)$ & $22(40.74 \%)$ \\
\hline Vitamin D Deficiency & $19(20.65 \%)$ & $13(34.21 \%)$ & $6(11.11 \%)$ \\
\hline
\end{tabular}

Values are mean $\pm \mathrm{SD}$ or $\mathrm{n}(\%)$. Mean represents all four quarterly measures of variable.

${ }^{A}$ Most recent status (Time Point 4)

${ }^{\ddot{y}}$ Cardiovascular disease includes coronary artery disease, my ocardial infarction, transient ischemic attack, cerebrovascular attack, atherosclerosis, deep vein thrombosis, peripheral vascular disease, peripheral artery disease, atril fibrillation, cardiac arrhy thmia, angina pectoris and congestive heart failure. 
Table 3. Functional Status and Laboratory Characteristics of Sample

\begin{tabular}{|c|c|c|c|c|c|}
\hline \multirow[b]{2}{*}{ Variables } & \multirow[b]{2}{*}{$\begin{array}{l}\text { Total / Mean Value } \\
\qquad \begin{array}{c}\text { (All TPs) } \\
n=92\end{array}\end{array}$} & \multicolumn{2}{|c|}{$\begin{array}{l}\text { Subjects Who Fell } \\
\qquad \mathrm{n}=38\end{array}$} & \multicolumn{2}{|c|}{$\begin{array}{l}\text { Subjects Who Did Not Fall } \\
\qquad \mathrm{n}=54\end{array}$} \\
\hline & & $\begin{array}{l}\text { Baseline } \\
\text { (TP1) } \\
\text { Oldest }\end{array}$ & $\begin{array}{c}\text { Termination } \\
\text { (TP4) } \\
\text { Recent }\end{array}$ & $\begin{array}{l}\text { Baseline } \\
\text { (TP1) } \\
\text { Oldest }\end{array}$ & $\begin{array}{l}\text { Termination } \\
\text { (TP4) } \\
\text { Recent }\end{array}$ \\
\hline Vision Status $^{\dot{A}}$ & $81(88.04 \%)$ & \multicolumn{2}{|c|}{$34(89.47 \%)$} & \multicolumn{2}{|c|}{$47(87.04 \%)$} \\
\hline Adequate & - & $24(63.16 \%)$ & $23(60.53 \%)$ & $25(46.30 \%)$ & $30(55.56 \%)$ \\
\hline Impaired & - & $9(23.68 \%)$ & $12(31.58 \%)$ & $18(33.33 \%)$ & $11(20.37 \%)$ \\
\hline Mod. Impaired & - & $4(10.53 \%)$ & $2(5.26 \%)$ & $5(9.26 \%)$ & $7(12.96 \%)$ \\
\hline Highly Impaired & - & $1(2.63 \%)$ & $1(2.63 \%)$ & $6(11.11 \%)$ & $6(11.11 \%)$ \\
\hline Assistance Level $^{\AA}$ & $89(96.74 \%)$ & \multicolumn{2}{|c|}{$37(97.37 \%)$} & \multicolumn{2}{|c|}{$52(96.30 \%)$} \\
\hline Independent & - & $6(15.79 \%)$ & $1(2.63 \%)$ & $2(3.70 \%)$ & $0(0.0 \%)$ \\
\hline Supervision & - & $1(2.63 \%)$ & $1(2.63 \%)$ & $1(1.85 \%)$ & $2(3.70 \%)$ \\
\hline Limited Assist. & - & $6(15.79 \%)$ & $5(13.16 \%)$ & $3(5.56 \%)$ & $4(7.41 \%)$ \\
\hline Extensive Assist. & - & $19(50.00 \%)$ & $23(60.53 \%)$ & $25(46.30 \%)$ & $25(46.30 \%)$ \\
\hline Total Dependence & - & $6(15.79 \%)$ & $8(21.05 \%)$ & $23(42.59 \%)$ & $23(42.59 \%)$ \\
\hline Facility Falls Score & $18.62 \pm 3.66$ & $17.47 \pm 4.27$ & $18.84 \pm 4.48$ & $18.84 \pm 3.71$ & $19.54 \pm 3.44$ \\
\hline Polypharmacy $^{\grave{A}}$ & $84(91.30 \%)$ & \multicolumn{2}{|c|}{$35(92.11 \%)$} & \multicolumn{2}{|c|}{$49(90.74 \%)$} \\
\hline Weight (kg) & $72.27 \pm 17.74$ & \multicolumn{2}{|c|}{$71.59 \pm 17.86$} & \multicolumn{2}{|c|}{$72.75 \pm 17.80$} \\
\hline BMI $\left(\mathrm{kg} / \mathrm{m}^{2}\right)$ & $26.65 \pm 5.98$ & \multicolumn{2}{|c|}{$26.43 \pm 5.96$} & \multicolumn{2}{|c|}{$26.81 \pm 6.05$} \\
\hline RDW (percentage) & $14.63 \pm 1.66$ & \multicolumn{2}{|c|}{$14.31 \pm 1.69$} & \multicolumn{2}{|c|}{$14.87 \pm 1.62$} \\
\hline $\mathrm{RBC}(\mathrm{M} / \mathrm{uL})$ & $3.88 \pm 0.49$ & \multicolumn{2}{|c|}{$3.96 \pm 0.52$} & \multicolumn{2}{|c|}{$3.84 \pm 0.48$} \\
\hline Hemoglobin $(\mathrm{g} / \mathrm{dL})$ & $11.96 \pm 1.51$ & \multicolumn{2}{|c|}{$12.25 \pm 1.62$} & \multicolumn{2}{|c|}{$11.74 \pm 1.40$} \\
\hline MCV (g/dL) & $92.83 \pm 4.86$ & \multicolumn{2}{|c|}{$93.62 \pm 5.42$} & \multicolumn{2}{|c|}{$92.23 \pm 4.37$} \\
\hline Fall Events & $0.99 \pm 2.04$ & $0.5 \pm 1.80$ & $1 \pm 1.27$ & - & - \\
\hline
\end{tabular}

Values are mean \pm SD or $\mathrm{n}(\%)$. Mean represents all four quarterly measures, except for Facility Falls Score and Fall Events variables. Time Point 1 and Time Point 4 means are represented for both subjects who did and did not fall.

$\mathrm{TP}=$ Time Point

ÀComputed as binary ("yes/no") for those who experienced any impairment or polypharmacy 
Table 4. Independent Predictors of Experiencing a Fall Event in Monovariate Logistic Regression Analysis

\begin{tabular}{lccc}
\hline & & $95 \%$ Confidence & \\
Variables & Odds Ratio & Interval & $P$ Value \\
\hline Average RDW & 0.789 & $0.578-1.077$ & 0.136 \\
Vision ImpairmentÀ & 0.679 & $0.421-1.098$ & 0.114 \\
Mobility Impairment $\AA$ & 0.589 & $0.339-1.022$ & 0.060 \\
Average Weight $(\mathrm{kg})$ & 0.996 & $0.973-1.020$ & 0.757 \\
Average BMI $\left(\mathrm{kg} / \mathrm{m}^{2}\right)$ & 0.989 & $0.922-1.062$ & 0.762 \\
Polypharmacy & 1.190 & $0.267-5.312$ & 0.819 \\
Average Facility Falls Score & 0.930 & $0.828-1.044$ & 0.222 \\
\hline
\end{tabular}

ÀUsing specific level of impairment from Time Point 4 
Table 5. Independent Predictors of Experiencing a Fall Event in Multivariate Logistic Regression Analysis

\begin{tabular}{lccc}
\hline & & $95 \%$ Confidence \\
Variables & Odds Ratio & Interval & $P$ Value \\
\hline Average RDW & 0.819 & $0.594-1.130$ & 0.225 \\
Vision ImpairmentÀ & 0.755 & $0.453-1.327$ & 0.353 \\
Mobility Impairment ̀̀ & 0.675 & $0.369-1.236$ & 0.203 \\
Average Weight $(\mathrm{kg})$ & 1.016 & $0.957-1.077$ & 0.611 \\
Average BMI $\left(\mathrm{kg} / \mathrm{m}^{2}\right)$ & 0.948 & $0.794-1.131$ & 0.555 \\
Polypharmacy & 0.636 & $0.111-3.621$ & 0.610 \\
Average Facility Falls Score & 1.015 & $0.887-1.161$ & 0.826 \\
\hline
\end{tabular}

ÀUsing specific level of impairment from Time Point 4 


\section{References}

Evans TC, Jehle D. The red blood cell distribution width. J Emerg Med. 1991; 9(1): 71-74.

National Heart, Lung, and Blood Institute: Types of blood tests. Austin (TX):

National Institutes of Health: 6 Jan 2012. Accessed August 3, 2013. Available from: http://www.nhlbi.nih.gov/health/health-topics/topics/bdt/types.html.

Nagurney JT, Brown DFM, Chang Y, et al. Use of diagnostic testing in the emergency department for patients presenting with non-traumatic abdominal pain. $J$ Emerg Med. 2003; 25(4): 363-71.

Osadnik T, Strzelczyk J, Hawranek M, et al. Red cell distribution width is associated with long-term prognosis in patients with stable coronary artery disease. $B M C$ Cardiovasc Disord. 2013; 13: 113-21.

Nishizaki Y, Yamagami S, Suzuki H, et al. Red blood cell distribution width as an effective tool for detecting fatal heart failure in super-elderly patients. Intern Med. 2012; 51: 2271-6.

Felker GM, Allen LA, Pocock SJ, et al. Red cell distribution width as a novel prognostic marker in heart failure: Data from the CHARM program and the Duke databank. J Am Coll Cardiol. 2007; 50: 40-7.

Tonelli M, Sacks F, Arnold M, et al. Relation between red blood cell distribution width and cardiovascular rate in people with coronary disease. Circulation. 2008; 117: $163-8$.

Ani C, Ovbiagele B. Elevated red blood cell distribution width predicts mortality in persons with known stroke. J Neurol Sci. 2009; 277(1-2): 103-8.

Cakal B, Gokmen A, Ustandag Y, et al. Red cell distribution width for assessment of activity of inflammatory bowel disease. Dig Dis Sci. 2009; 54: 842-7.

Clarke K, Sagunarthy R, Kansal S. RDW as an additional marker in inflammatory bowel disease/undifferentiated colitis. Dig Dis Sci. 2008; 53: 2521-3.

Malandrino N, Wu WC, Taveira TH, et al. Association between red blood cell distribution width and macrovascular and microvascular complications in diabetes. Diabetologia. 2012; 55: 226-35.

Maruyama S, Hirayama C, Yamamoto S, et al. Red blood cell status in alcoholic and non-alcoholic liver disease. J Lab Clin Med. 2001; 138: 332-7.

kenol K, Saylam B, Kocaay F, et al. Red cell distribution width as a predictor of mortality in acute pancreatitis. Am J Emerg Med. 2013; 31: 687-9.

Sil aja M, Pehar M, ṇerek L, et al. Red blood cell distribution width as a prognostic marker of mortality in patients on chronic dialysis: a single center, prospective longitudinal study. Croat Med J. 2013; 54: 25-32.

Weiss G, Goodnough LT. Anemia of chronic disease. N Engl J Med. 2005; 352: 1011-23.

Förhécz Z, Gombos T, Borgulya G, et al. Red cell distribution width in heart failure: prediction of clinical events and relationship with markers of ineffective erythropoiesis, inflammation, renal function, and nutritional state. Am Heart J. 2009; 158(4): 659-66. 
Al-Najjar Y, Goode KM, Zhang J, et al. Red cell distribution width: an inexpensive and powerful prognostic marker in heart failure. Eur J Heart Fail. 2009; 11(12): 1155-62.

Adams KF, Mehra MR, Oren RM, et al. Prospective evaluation of the association between cardiac troponin $\mathrm{T}$ and markers of distributed erythropoiesis in patients with heart failure. Am Heart J. 2010; 160: 1142-8

Wen Y. High red blood cell distribution width is closely associated with risk of carotid artery atherosclerosis in patients with hypertension. Exp Clin Cardiol. 2010; 15(3): 37-40.

Cavusoglu E, Chopra V, Gupta A, et al. Relation between red blood cell distribution width (RDW) and all-cause mortality at two years in an unselected population referred for coronary angiography. Int J Cardiol. 2010; 141(2): 141-6.

Maurer MS, Burcham J, Cheng H. Diabetes mellitus is associated with an increased risk of falls in elderly resident of a long-term care facility. J Gerontol A Biol Sci Med Sci. 2005; 60(9): 1157-62.

Pierce CN, Larson DF. Inflammatory cytokine inhibition of erythropoiesis in patients implanted with a mechanical circulatory assist device. Perfusion. 2005; 20: 83-90. Ferrucci L, Guralnik JM, Woodman RC, et al. Proinflammatory state and circulating erythropoietin in persons with and without anemia. Am J Med. 2005; 118(11): 1288. Lippi G, Targher G, Montagnana M, et al. Relation between red blood cell distribution width and inflammatory biomarkers in a large cohort of unselected outpatients. Arch Pathol Lab Med. 2009; 133(4): 628-32.

Ridker PM, Hennekens CH, Buring JE, et al. C-reactive protein and other markers of inflammation in the prediction of cardiovascular disease in women. $N$ Engl J Med. 2000; 342(12): 836-43.

Ridker PM, Cushman M, Stampfer MJ, et al. Inflammation, aspirin, and the risk of cardiovascular disease in apparently healthy men. NEJM. 1997; 336(14): 973-9. Ridker PM, Rifai N, Rose L, et al. Comparison of C-reactive protein and low-density lipoprotein cholesterol levels in the prediction of first cardiovascular events. NEngl J Med. 2002; 347(20): 1557-65.

Emerging Risk Factors Collaboration, Kaptoge S, Di Angelantonio E, Lowe G, et al. C-reactive protein concentration and risk of coronary heart disease, stroke, and mortality: An individual participant meta-analysis. Lancet. 2010; 375(9709): 13240.

Rifai N, Ridker PM. High-sensitivity C-reactive protein: A novel and promising marker of coronary heart disease. Clin Chem. 2001; 47(3): 403-11.

Puts MT, Visser M, Twisk JW, et al. Endocrine and inflammatory markers as predictors of frailty. Clin Endocrinol (Oxf). 2005; 63(4): 403-11.

Patel KV, Ferrucci L, Ershler WB, et al. Red blood cell distribution width and the risk of death in middle-aged and older adults. Arch Intern Med. 2009; 169(5): 51523.

Patel KV, Semba RD, Ferrucci L, et al. Red cell distribution width and mortality in older adults: A meta-analysis. J Gerontol A Biol Sci Med Sci. 2010; 65A(3): 258-65. National Center for Injury Prevention and Control. Webï based Injury Statistics Query and Reporting System (WISQARS). Centers for Disease Control and 
Prevention Website. Available from: http://www.cdc.gov/injury/WISQARS/. Accessed August 15, 2013.

(34) Tromp AM, Pluijm SMF, Smit JH, et al. Fall-risk screening test: a prospective study on predictors for falls in community-dwelling elderly. J Clin Epidemiol. 2001; 54(8):837ï 844.

(35) Falls among older adults: An overview. Centers for Disease Control and Prevention Website. Available from: http://www.cdc.gov/homeandrecreationalsafety/ falls/adultfalls.html. Updated September 20, 2013. Accessed October 31, 2013.

(36) Rubenstein LZ, Josephson KR, and Robbins AS. Falls in the nursing home. Ann Intern Med. 1994; 121: 442-51.

Fuller GC. Falls in the elderly. Am Fam Physician. 2000; 61(7): 2159-68. A profile of older Americans: 2011. Washington D.C.: Administration on Aging, U.S. Department of Health and Human Services. 2011; P:15.

Rubenstein LZ. Preventing falls in the nursing home. JAMA. 1997; 278(7):595ï 6. Rubenstein LZ. Falls in older people: Epidemiology, risk factors, and strategies for prevention. Age and Ageing. 2006; 35-S2: ii37-ii41.

French DD, Werner DC, Campbell RR, et al. A multivariate fall risk assessment model for VHA nursing homes using the minimum data set. J Am Med Dir Assoc. 2007; 8(2): 115-22.

Falls in Nursing Homes. Centers for Disease Control and Prevention Website. Available from: http://www.cdc.gov/homeandrecreationalsafety/falls/nursing.html. Published and Updated: February 29, 2012. Accessed: August 19, 2014.

Suzuki M, Ohyama N, Yamada K, et al. The relationship between fear of falling activities of daily living and quality of life among elderly individuals. Nurs Health Sci. 2002; 4: 155-161.

Sterling DA, O'Connor JA, Bonadies J. Geriatric falls: injury severity is high and disproportionate to mechanism. J Trauma. 2001; 50(1): 116 ï 9.

Alexander BH, Rivara FP, Wolf ME. The cost and frequency of hospitalization for fallï related injuries in older adults. Am J Public Health 1992; 82(7):1020ї 3.

Stalenhoef PA, Diederiks JPM, Knottnerus JA, et al. A risk model for the prediction of falls in community-dwelling elderly: A prospective cohort study. J Clin Epi. 2002; 55: 1088-94.

Stevens JA, Corso PS, Finkelstein EA, et al. The costs of fatal and non-fatal falls among older adults. Inj Prev. 2006; 12: 290-5.

Sterling DA, OâConnor JA, Bonadies J. Geriatric falls: Injury severity is high and disproportionate to mechanism. J Trauma. 2001; 50: 116-9.

Stevens JA, Corso PS, Finkelstein EA, Miller TR. The costs of fatal and nonfatal falls among older adults. Injury Prevention. 2006; 12:290ї 5.

Rawsky E. Review of the literature on falls among the elderly. Image J Nurs Sch. 1998; 30: 47-52.

Costs of Falls Among Older Adults. Centers for Disease Control and Prevention (CDC) Website. Available from: http://www.cdc.gov/HomeandRecreationalSafety/ Falls/fallcost.html. Updated March 5, 2014. Accessed October 24, 2014. Calculators: Life Expectancy. Woodlawn (MD): United States Social Security Administration. Accessed: 2014 Jan 23. Available from: http://www.ssa.gov/ planners/lifeexpectancy.htm. 
Bonnick SL. Osteoporosis in men and women. Clinical Cornerstone. 2006; 8(1): 28-39.

Berg WR, Alessio HM, Mills EM, et al. Circumstances and consequences of falls in independent community dwelling older adults. Age and Ageing. 1997; 25: 261-8. Bell AJ, Talbot-Stern JK, Hennessy A. Characteristics and outcomes of older patients presenting to the emergency department after a fall: a retrospective analysis. Medical Journal of Australia. 2000; 173(4):176ï 7.

Vellas BJ, Wayne SJ, Romero LJ, et al. Fear of falling and restriction of mobility in elderly fallers. Age and Ageing. 1997; 26:189ї 193.

Lenze EJ, Mulsant BH, Shear K, et al. Comorbidity of depression and anxiety disorders in later life. Depress Anxiety. 2001; 14: 86-93.

Nourhashémi F, Andrieu S, Gillette-Guyonnet S, et al. Instrumental activities of daily living as a potential marker of frailty: A study of 7364 community-dwelling elderly women (the EPIDOS study). J Gerontol A Biol Sci Med Sci. 2001; 56(7): M448-53.

Guidelines for the prevention of falls in older adult persons. American Geriatrics Society, British Geriatrics Society, and American Academy of Orthopedic Surgeons Panel on Falls Prevention. J Am Geriatr Soc. 2001; 49: 664-72.

Rubenstein LZ, Josephson KR. The epidemiology of falls and syncope. Clin Geriatr Med. 2002; 18: 141-158.

Lord SR, Clark RD, Webster IW. Physiological factors associated with falls in an elderly population. J Am Geriatr Soc. 1991; 39: 1194-200.

Lord SR, Sherrington C, and Menz HB. Falls in older people. New York, NY: Cambridge University Press; 2001. p. 4.

State Operations Manual: Appendix PPð Guidance to Surveyors for Long Term Care Facilities. Centers for Medicare \& Medicaid Website. http://www.cms.gov/ Regulations-and-Guidance/Guidance/Manuals/Internet-Only-Manuals-IOMsItems/CMS1201984.html. Updated: April 4, 2014. Accessed: August 28, 2014. Healthcare Risk Control ï Falls. Emergency Care Research Institute. https://www.ecri.org/Documents/RM/HRC_TOC/SafSec2.pdf. Published: March 2009. Accessed: August 28, 2014.

Stapleton C, Hough P, Oldmeadow L, et al. Four-item fall risk screening tool for subacute and residential aged care: The first step in fall prevention. Australas $J$ Ageing. 2009; 28(3): 139-43.

OASIS-C Guidance Manual. Centers for Medicare \& Medicaid Services. http://www.cms.gov/Medicare/Quality-Initiatives-Patient-Assessment-Instruments/ HomeHealthQualityInits/HHQIOASISUserManual.html. Published: September 2009. Updated: July 22, 2014. Accessed: August 22, 2014.

OASIS Questions \& Answers. OASIS Answers. http://www.oasisanswers.com/ downloads/CMS_OCCB_4th_Qtr_QAs_01_19_2010.pdf. Published: January 19, 2010. Accessed: August 22, 2014.

Oliver D, Daly F, Martin FC, et al. Risk factors and risk assessment tools for falls in hospital in-patients: A systematic review. Age and Ageing. 2004; 33: 122-30.

Scott V, Votova K, Scanlan A, et al. Multifactorial and functional mobility assessment tools for fall risk among older adults in community, home-support, longterm and acute care settings. Age Ageing. 2007; 36(2): 130-9. 
(70) Good Practices in Preventing Patient Falls: A Collection of Case Studies. Joint Commission International. $1^{\text {st }}$ ed. Oak Brook (IL): Joint Commission Resources; 2007. p 17-30.

(71) Perell KL, Nelson A, Goldman RL, et al. Fall risk assessment measures: An analytic review. J Gerontol. 2001; 56A(12): M761-6. test is the optimal screening tool to predict falls in frail community-dwelling older people? Gerontology. 2009; 55: 533-8.

Vassallo M, Stockdale R, Sharma JC, et al. A comparative study of the use of four fall risk assessment tools on acute medical wards. J Am Geriatr Soc. 2005; 53(6): 1034-8.

Shimada H, Suzukawa M, Ishizaki T, et al. Relationship between subjective fall risk assessment and falls in fall-related fractures in frail elderly people. BMC Geriatr. 2011; 11: 40-8.

Meyer G, Köpke S, Haastert B, et al. Comparison of a fall risk assessment tool with nursesôjudgment alone: A cluster-randomized controlled trial. Age Ageing. 2009; 38(4): 417-23.

Nordin E, Lindelöf N, Rosendahl E, et al. Prognostic validity of the Timed Up-andGo test, a modified Get-Up-and-Go test, staffôs global judgement and fall history in evaluating fall risk in residential care facilities. Age Ageing. 2008; 37(4): 442-8. Vassallo M, Poynter L, Sharma JC, et al. Fall risk-assessment tools compared with clinical judgment: An evaluation in a rehabilitation ward. Age Ageing. 2008; 37(3): 277-81.

Herman T, Giladi N, Gurevich T, et al. Gait instability and fractal dynamics of older adults with a ñcautiousò gait: Why do certain older adults walk fearfully? Gait and Posture. 2005; 21: 178-85.

Hausdorff JM, Nelson ME, Kaliton D, et al. Etiology and modification of gait instability in older adults: A randomized controlled trial of exercise. J Appl Physiol. 2001; 90: 2117-29.

van Iersel MB, Munneke M, Esselink RA, et al. Gait velocity and the Timed-Up-andGo test were sensitive to changes in mobility in frail elderly patients. J Clin Epidemiol. 2008; 61(2): 186-91.

Podsiadlo D, Richardson S. The timed ñUp \& Goò. A test of basic functional mobility for frail elderly persons. J Am Geriatr Soc. 1991 39(2): 142-8.

Pavol MJ, Owings TM, Foley KT, et al. Influence of lower extremity strength of healthy older adults on the outcome of an induced trip. J Am Geriatr Soc. 2002; 50(1): 256-62.

Moreland JD, Richardson JA, Goldsmith CH, et al. Muscle weakness and falls in older adults: A systematic review and meta-analysis. J Am Geriatr Soc. 2004; 52: 1121-9.

Daubney ME, Culham EG. Lower-extremity muscle force and balance performance in adults aged 65 years and older. Phys Ther. 1999; 79: 1177-85.

Chandler JM, Duncan PW, Kochersberger G, et al. Is lower extremity strength gain associated with improvement in physical performance and disability in frail, community-dwelling elders? Arch Phys Med Rehabil. 1998; 79(1): 24-30. 
(86)

Carmeli E, Reznick AZ, Coleman R, et al. Muscle strength and mass of lower extremities in relation to functional abilities in elderly adults. Gerontology. 2000; 46: 249-57.

Robbins AS, Rubenstein LZ, Josephson KR, et al. Predictors of falls among elderly people. Results of two population-based studies. Arch Intern Med. 1989; 149(7): 1628-33.

Stuck AE, Walthert JM, Nikolaus T, et al. Risk factors for functional status decline in community-living elderly people: A systematic literature review. Soc Sci Med. 1999; 48(4): 445-69.

Hita-Contreras F, Martínez-Amat A, Lomas-Vega R, et al. Relationship of body mass index and body fat distribution with postural balance and risk of falls in Spanish postmenopausal women. Menopause. 2013; 20(2): 202-8.

Matrangola SL, Madigan ML. The effects of obesity on balance recovery using an ankle strategy. Hum Mov Sci. 2011; 30(3): 584-595.

Ensrud KE, Ewing SK, Taylor BC, et al. Frailty and risk of falls, fracture, and mortality in older women: the study of osteoporotic fractures. J Gerontol A Biol Sci Med Sci. 2007; 62(7): 744-51.

Gallagher D, Ruts E, Viser M, et al. Weight stability masks sarcopenia in elderly men and women. Am J Physiol Endocrinol Metab. 2000; 279: E366-E375.

Nguyen TV, Eisman JA, Kelly PJ, et al. Risk factors for osteoporotic fractures in elderly men. Am J Epidemiol. 1996; 144(3): 255-63.

Ryynänen O-P. Health, functional capacity, health behavior, psychosocial factors and falling in old age. Public Health. 1994; 108: 99-110.

Honeycutt PH, Ramsey P. Factors contributing to falls in elderly men living in the community. Geriatr Nurs. 2002; 23(5): 250-5.

Morris V, Wagg A. Lower urinary tract symptoms, incontinence and falls in elderly people: Time for an intervention study. Int J Clin Pract. 2007; 61(2): 320-3.

Chiarelli PE, Mackenzie LA, and Osmotherly PG. Urinary incontinence is associated with an increase in falls: A systematic review. Aust J Physiother. 2008; 55: 89-95.

$\mathrm{Hu}$ TW, Wagner TH, Bentkover JD, et al. Costs of urinary incontinence and overactive bladder in the United States: A comparative study. Urology. 2004; 63: 461-5.

Asplund R. Nocturia in relation to sleep, health, and medical treatment in the elderly. BJU Int. 2005; 96(Suppl 1): 15-21.

Rankin JK, Woollacott MH, Shumway-Cook A, et al. Cognitive influence on postural stability: A neuromuscular analysis in young and older adults. J Gerontol. 2000; 55(3): M112-M119.

Brown LA, Shumway-Cook A, Woollacott MH. Attentional demands and postural recovery: the effects of aging. J Gerontol. 1999; 54(4): M165-M171.

Welmerink DB, Longstreth WT Jr, Lyles MF, et al. Cognition and the risk of hospitalization for serious falls in the elderly: Results from the Cardiovascular Health Study. J Gerontol A Biol Sci Med Sci. 2010; 65(11): 1242-9.

Whitney J, Close JC, Jackson SH, et al. Understanding risk of falls in people with cognitive impairment living in residential care. J Am Med Dir Assoc. 2012; 13(6): 535-40. 
(104) Stevens JA, Thomas K, Teh L, et al. Unintentional fall injuries associated with walkers and canes in older adults treated in U.S. emergency departments. $J \mathrm{Am}$ Geriatr Soc. 2009; 57(8): 1464-9.

(105) Harwood RH. Visual problems and falls. Age Ageing. 2001; 30-S4: 13-8.

(106) Koski K, Luukinen H, Laippala P, et al. Risk factors for major injurious falls among the home-dwelling elderly by functional abilities. A prospective population-based study. Gerontology. 1998; 44(4): 232-8.

(107) De Boer MR, Plujim SMF, Lips P, et al. Different aspects of visual impairment as risk factors for falls and fractures in older men and women. J Bone Miner Res. 2004; 19(9): 1539-47.

(108) Lord SR. Visual risk factors for falls in older people. Age Ageing. 2006; 35 Suppl 2: ii42-ii45.

(109) Lord SR, Dayhew J, Howland A. Multifocal glasses impair edge-contrast sensitivity and depth perception and increase the risk of falls in older people. J Am Geriatr Soc. 2002; 50(11): 1760-6.

(110) Bischoff-Ferrari HA, Dawson-Hughes B, Willett WC, et al. Effect of vitamin D on falls: A meta-analysis. JAMA. 2004; 291(16): 1999-2006.

(111) Broe KE, Chen TC, Weinberg J, et al. A higher dose of vitamin D reduces the risk of falls in nursing home residents: A randomized, multiple-dose study. J Am Geriatr Soc. 2007; 55(2): 234-9.

(112) Pfeifer M, Begerow B, Minne HW, et al. Effects of a short-term vitamin D and calcium supplementation on body sway and secondary hyperparathyroidism in elderly women. J Bone Miner Res. 2000; 15(6): 1113-8.

(113) Shuler FD, Schlierf T, Wingate M. Preventing falls with vitamin D. WV Med J. 2014; 110(3): 10-2.

(114) Ceglia L. Vitamin D and its role in skeletal muscle. Curr Opin Clin Nutr Metab Care. 2009; 12(6): 628-33.

(115) Pfeifer M, Begerow B, Minne HW, et al. Effects of a long-term vitamin D and calcium supplementation on falls and parameters of muscle function in communitydwelling older individuals. Osteoporos Int. 2009; 20(2): 315-22.

(116) Dawson-Hughes B, Harris SS, Krall EA, et al. Effect of calcium and vitamin D supplementation on bone density in men and women 65 years of age or older. N Engl J Med. 1997; 337: 670-6.

(117) Ziere G, Dieleman JP, Hofman A, et al. Polypharmacy and falls in the middle age and elderly population. Br J Clin Pharmacol. 2006; 61(2): 218-23.

(118) Weiner DK, Hanlon JT, Studenski SA. Effects of central nervous system polypharmacy on falls liability in community-dwelling elderly. Gerontology. 1998; 44(4): 217-21.

(119) Woolcott JC, Richardson KJ, Weins MO, et al. Meta-analysis of the impact of 9 medication classes on falls in the elderly persons. Arch Intern Med. 2009; 169(21): 1952-60.

(120) American Geriatrics Society 2012 Beers Criteria Update Expert Panel. American Geriatrics Society updated Beers Criteria for potentially inappropriate medication use in older adults. J Am Geriatr Soc. 2012; 60(4): 616-31.

(121) Beers MH. Explicit criteria for determining potentially inappropriate medication use by the elderly. An update. Arch Intern Med. 1997; 157(14): 1531-6. 
(122) Myers AH, Young Y, Langlois JA. Prevention of falls in the elderly. Bone. 1996; 18(1): 87S-101S.

(123) Landi F, Onder G, Cesari M, et al. Psychotropic medications and risk for falls among community-dwelling frail older people: An observational study. J Gerontol A Biol Med Sci. 2005; 60(5): 622-6.

(124) Thapa PB, Gideon P, Cost TW, et al. Antidepressants and the risk of falls among nursing home residents. NEJM. 1998; 339(13): 875-82.

(125) Echt MA, Samelson EJ, Hannan MT, et al. Psychotropic drug initiation or increased dosage and the acute risk of falls: a prospective cohort study or nursing home residents. BMC Geriatr. 2013; 13(19): 1-8.

(126) Sharkey LM, Czajkowski C. Individually monitoring ligand-induced changes in the structure of the $\mathrm{GABA}_{\mathrm{A}}$ receptor at benzodiazepine binding site and non-binding-site interfaces. Mol Pharmacol. 2008; 74: 203-12.

(127) Wang PS, Bohn RL, Glynn RJ, et al. Hazardous benzodiazepine regimens in the elderly: effects of half-life, dosage, and duration on risk of hip fracture. $\mathrm{Am} J$ Psychiatry. 2001; 158: 892-8.

(128) Pariente A, Dartigues JF, Benichou J, et al. Benzodiazepines and injurious falls in community dwelling elders. Drugs Aging. 2008; 25(1): 61-70.

(129) Hartikainen S, Lönnroos E, Louhivuori K. Medication as a risk factor falls: critical systematic review. J Gerontol A Biol Sci Med Sci. 2007; 62(10): 1172-81.

(130) Luukinen H, Koski K, Laippala, et al. Risk factors for recurrent falls in the elderly in long-term institutional care. Public Health. 1995; 109(1): 57-65.

(131) Schwartz AV, Hillier TA, Sellmeyer DE, et al. Older women with diabetes have a higher risk of falls: A prospective study. Diabetes Care. 2002; 25(10): 1749-54.

(132) Lawlor DA, Patel R, Ebrahim S. Association between falls in elderly women and chronic diseases and drug use: Cross sectional study. BMJ. 2003; 327(74170): 7127.

(133) Grant BJ, Kudalkar DP, Muti P, et al. Relation between lung function and RBC distribution width in a population-based study. Chest. 2003; 124(2): 494-500.

(134) Fenech AG, Ellul-Micallef R. Selenium, glutathione peroxidases and superoxide dismutase in maltese asthmatic patients: Effect of glucocorticoid administration. Pulm Pharmacol Ther. 1998; 11(4): 301-8.

(135) Graafmans WC, Ooms ME, Hofstee MA, et al. Falls in the elderly: A prospective study of risk factors and risk profiles. Am J Epidemiol. 1996; 143(11): 1129-36.

(136) Lau DT, Kasper JD, Potter DEB, et al. Potentially inappropriate medication prescriptions among elderly nursing home residents: Their scope and associated resident and facility characteristics. Health Serv Res. 2004; 39(5): 1257-76.

(137) Tamura BK, Bell CL, Lubimir K, et al. Physician intervention for medication reduction in a nursing home: The polypharmacy outcomes project. J Am Med Dir Assoc. 2011; 12(5): 326-30.

(138) Overcash JA, Beckstead J. Predicting falls in older patients using components of a comprehensive geriatric assessment. Clin J Oncol Nurs. 2008; 12(6): 941-9.

(139) Starr JM, Leaper SA, Murray AD, et al. Brain white matter lesions detected by magnetic resonance imaging are associated with balance and gait speed. J Neurol Neurosurg Psychiatry. 2003; 74(1): 94-8. 
(140) Moussavi S, Chatterji S, Verdes E, et al. Depression, chronic diseases, and decrements in health: Results from the World Health Surveys. Lancet. 2007; 370(9590): 851-8.

(141) Sánchez-Chaparro MA, Calvo-Bonacho E, González-Quintela A, et al. Higher red blood cell distribution width is associated with metabolic syndrome: Results of the Ibermutuaur CArdiovascular RIsk assessment study. Diabetes Care. 2010; 33(3): e40.

(142) Vayá A, Carmona P, Badia N, et al. Association between high red blood cell distribution width and metabolic syndrome: Influence of abdominal obesity. Clin Hemorheol Microcirc. 2011; 47(1): 75-7.

(143) Ory MG, Smith ML, Ahn S, et al. National study of chronic disease selfmanagement: age comparison of outcome findings. Health Educ Behav. 2014; 41(1 Suppl): 34 S-42S.

(144) MDS 3.0 RAI UsersôManual (v 1.11), Chapter 3 ï Section K: Swallowing/Nutrition Status. Denver (CO): American Association of Nurse Assessment Coordination (AANAC): 2000-2014. Accessed June 20, 2014. Available from: http://www.aanac.org/information-resources/mds30/the-rai-manual.

(145) Sullivan DH, Johnson Le, Bopp MM, et al. Prognostic significant of monthly weight fluctuations among older nursing home residents. J Gerontol A Biol Sci Med Sci. 2004; 59(6): M633-9.

(146) Blanc-Bisson C, Dechamps A, Gouspillou G, et al. A randomized controlled trial on early physiotherapy intervention versus usual care in acute care unit for elderly: Potential benefits in light of dietary intakes. J Nutr Health Aging. 2008; 12(6): 3959.

(147) Janssen I, Katzmarzyk PT, Ross R. Body mass index is inversely related to mortality in older people after adjustment for waist circumference. J Am Geriatr Soc. 2005; 53(12): 2112-8.

(148) Hammarsten O, Jacobsson S, Fu M. Red cell distribution width in chronic heart failure: A new independent marker for prognosis? Eur J Heart Fail. 2010; 12(3): 213-4.

(149) Mahoney JE, Sager MA, Jalaluddin M. Use of an ambulation assistive device predicts functional decline associated with hospitalization. J Gerontol A Biol Sci Med Sci. 1999; 54(2): M83-8.

(150) Sackett DL. Bias in analytical research. J Chron Dis. 1979; 32: 51-63.

(151) Jones AL, Dwyer LL, Bercovitz AR, et al. The National Nursing Home Survey: 2004 overview. Vital Health Stat 13. 2009; 167: 1-155.

(152) Kim J, Kim K, Lee JH, et al. Red blood cell distribution width as an independent predictor of all-cause mortality in out of hospital cardiac arrest. Resuscitation. 2012; 83(10): 1248-52.

(153) Bazick HS, Chang D, Mahadevappa K, et al. Red cell distribution width and allcause mortality in critically ill patients. Crit Care Med. 2011; 39(8): 1913-21.

(154) Wilson RS, McCann JJ, Li Y, et al. Nursing home placement, day care use, and cognitive decline in Alzheimerô disease. Am J Psychiatry. 2007; 164(6): 910-5. Miller SC, Gozalo P, Mor V. Hospice enrollment and hospitalization of dying nursing home patients. Am J Med. 2001; 111(1): 38-44. 
(156) Ye Z, Smith C, Kullo IJ. Usefulness of red cell distribution width to predict mortality in patients with peripheral artery disease. Am J Cardiol. 2011; 107(8): 1241-5.

(157) Wall JC, Bell C, Campbell S, et al. The timed get-up-and-go test revisited: Measurement of the component tasks. J Rehabil Res Dev. 2000; 37(1): 109-14.

(158) Shumway-Cook A, Brauer S, Woollacott M. Predicting the probability for falls in community-dwelling older adults using the timed up \& go test. Phys Ther. 2000; 80: 896-903.

(159) Thorbahn LDB, Newton RA. Use of the Berg balance test to predict falls in elderly persons. Phys Ther. 1996; 76: 576-83.

(160) Lajoie Y, Gallagher SP. Predicting falls within the elderly community: Comparison of postural sway, reaction time, the Berg balance scale and the Activities-specific Balance Confidence (ABC) scale for comparing fallers and non-fallers. Arch Gerontol Geriatr. 2004; 38: 11-26.

(161) Hauer K, Yardley L, Beyer N, et al. Validation of the falls efficacy scale and falls efficacy scale international in geriatric patients with and without cognitive impairment: Results of self-report and interview-based questionnaires. Gerontology. 2010; 56: 190-9.

(162) STEADI (Stopping Elderly Accidents, Deaths, \& Injuries) Toolkit for Healthcare Providers. Centers for Disease Control and Prevention. Accessed January 27, 2014. Available from: http://www.cdc.gov/homeandrecreationalsafety/ Falls/steadi/index.html.

(163) Jones CJ, Rikli RE, Beam WC. A 30-s chair stand test as a measure of lower body strength in community-residing older adults. Res Q Exerc Sport. 1999; 70(2): 113-9.

(164) Common Screening and Assessment Tools. Hamilton County Fall Prevention Task Force: Ohio Department of Health. Accessed January 27, 2014. Available from: http://www.fallpreventiontaskforce.org/tools.htm.

(165) Lewis C. Balance, gait test proves simple yet useful. P.T. Bulletin. 1993; 2(10): 9, 40 .

(166) Tinetti ME. Performance-oriented assessment of mobility problems in elderly patients. JAGS. 1986; 34: 119-26.

(167) Kegelmeyer DA, Kloos AD, Thomas KM, et al. Reliability and validity of the Tinetti mobility test for individuals with Parkinson disease. Phys Ther. 2007; 87: 1369-78.

(168) Khasnis A, Gokula RM. Rombergố test. J Postgrad Med. 2003; 49: 169.

(169) Hardcastle P, Nade S. The significance of the Trendelenburg test. J Bone Joint Surg Br. 1985; 67-B: 741-6.

(170) Jonsson E, Henriksson M, Hirschfeld H. Does the functional reach test reflect stability limits in elderly people? J Rehabil Med. 2002; 35: 26-30.

(171) Nandy S, Parsons S, Cryer C, et al. Development and preliminary examination of the predictive validity of the falls risk assessment tool (FRAT) for use in primary care. $J$ Public Health. 2004; 26(2): 138-43. 